\title{
Effects of interconnections between timber floor elements: dynamic and static evaluations of structural scale tests
}

\author{
Sveinung Nesheim ${ }^{1}\left[\right.$ [D $\cdot$ Kjell Arne Malo $^{2} \cdot$ Nathalie Labonnote $^{3}$
}

Received: 28 September 2020 / Accepted: 15 April 2021 / Published online: 6 May 2021

(c) The Author(s) 2021

\begin{abstract}
Long-span timber floor elements increase the flexibility of a building and exhibit a significant market potential. Timber floor elements are endeavouring to fulfil this potential, but building projects employing long-span timber floors have encountered drawbacks. High costs and vibration performance are challenging, and the timber industry is under substantial pressure to find attractive solutions for building components with otherwise favourable environmental features. Only a few existing studies have investigated serviceability sensitivity in relation to timber floor connections. Interconnections are inexpensive to produce and install and may offer a resource-efficient approach to improving serviceability performance. In the present study, the effect of interconnections is investigated in a full-scale structural test. Floor elements positioned in different configurations have been tested for static and dynamic performance using different types of interconnections. The observed effects of interconnection types vary according to the configuration and direction of mode shapes, and are assessed in terms of shift in frequency, damping and resonant energy. These can all be utilised in combination with observed differences in the deflection parameter. The present work demonstrates that connections between timber elements have significant effects on timber floor serviceability and may offer interesting solutions to improve the vibration performance of long-span timber floors.
\end{abstract}

\section{Introduction}

The greater utilisation of timber in the building sector has the potential to contribute to reductions in greenhouse gas (GHG) emissions, which represent a major and universal challenge to the sector. Global population growth and urbanization are placing increasing demands on a need for multistorey, space-efficient, sustainable and flexible buildings. For timber to become an attractive building material under current market conditions, innovative and competitive concepts must be developed, proven and effectively marketed. The development of open architectures and long-spanning

Sveinung Nesheim

sne@ntnu.no

Kjell Arne Malo

kjell.malo@ntnu.no

Nathalie Labonnote

nathalie.labonnote@sintef.no

1 Norwegian University of Science and Technology (NTNU), Richard Birkelandsvei 1a, 7491 Trondheim, Norway

2 NTNU, Trondheim, Norway

3 Sintef Community, Trondheim, Norway primary structures has the potential to enhance the competitiveness and environmental performance of timber-based buildings. Such features increase the scope of compliant building typologies, functionality and potential interior layout permutations (Gosling et al. 2013). It is currently technically feasible to design a timber floor of ten metres span with acceptable acoustic performance. The challenge is however to offer the market floor elements with competitive designs at an acceptable commercial risk with proven static and dynamic performance of serviceability.

Numerous criteria may be used to assess timber floor serviceability, and although the physical principles are similar to human discomfort during horizontal motion, the topic is less matured and no international agreement of evaluating serviceability has been established. In general terms, floor serviceability criteria involve the use of a deflection constraint for flatness, and a frequency constraint that addresses human perception. The criterion commonly used by $\mathrm{Hu}$ and Chui (2004) is based solely on these two constraints. However, most other approaches employ a dynamic constraint, either in the form of a Vibration Dose Value (ISO 2007), an RMS-acceleration for resonant response (Smith et al. 2009), or an RMS-velocity for transient response (Ohlsson 1988) that serves to improve the description of what are perceived 
to be troublesome vibrations. Recent developments resulting from work carried out in Working Group 3 of the CEN TC 250/SC 5 (CEN 2018a) are likely to introduce more adaptable criteria that incorporate categorisation into performance classes. As is clear from published reviews (Zhang et al. 2013; Negreira et al. 2015), all documented methods exhibit benefits and drawbacks and will lead to different floor designs for the same application.

The second major challenge facing the timber floor construction sector is how to boost serviceability and market competitiveness while keeping resource consumption low. A focused exploration of the solution space related to typologies and innovatively engineered timber products is a challenging task. A less studied approach has been the assessment and utilisation of performance differences when comparing single floor elements with contiguous flooring systems. The assembly of floor elements to form a functional flooring system may involve the use of a variety of connections and configurations. The use of connections may represent a cost-effective approach to altering the dynamic response of a flooring system without changing the overall design of the basic floor element.

Only very few investigations have been published on the topic of connections, and generally with the aim of establishing guidelines governing the cost-efficient adaptation of floor elements to different applications. Comparisons of differences in performance of floor elements with continuous and discontinuous sheeting have been presented in Burch et al. (2016), and similar results are expected for comparisons between floor elements. Weckendorf and Smith (2012) present a study of the effects of both interconnecting elements and intermediate supports in the context of Cross Laminated Timber (CLT) construction. Ebadi et al. (2016) and Ebadi (2017) document the results of a study of the low-amplitude dynamic responses of a one-way spanning floor element. One out of nine floor configurations (Floor 5 in their study), demonstrated the effect of interconnected adjacent floor elements contributing towards increased composite action. This study concluded that the first fundamental frequency and deflection parameters remain unchanged, but that frequency spacing between adjacent modes decreases for higher mode shapes. In another study carried out by Weckendorf et al. (2016a), mode shapes, frequencies and damping are interpreted to be strongly dependent on the construction details of end and edge restraints, as well as the method of interconnection between the elements making up the flooring system. In Weckendorf et al. (2016b), the authors address the influence on boundary conditions of timber floors in the context of both design strategies and damping. Ignoring the semi-rigid connections between CLT elements, by assuming either an absence of connections or full continuity, leads to significant inaccuracies in predictions of mode shapes and frequencies. This is also pointed out in a study by Ussher et al. (2017), which investigated half-lap screwed interconnections. In Labonnote and Malo (2010), a main effects analysis indicated that connection stiffness and element width exert a significant influence on the $\mathrm{Hu}$ and Chui criterion (Hu and Chui 2004). This study demonstrated that the vibration properties of floor elements improve with increasing width, and that the influence of interconnections between elements is closely related to element width. Weckendorf et al. (2014) investigated the effects of on-site horizontal transmissions within floor substructures forming contiguous flooring systems, but the boundary conditions are not comparable.

The objective of this study is to adapt the comfort performance of elements in a flooring system in a way that reduces costs and environmental impact. This has been achieved by investigating whether interconnections between timber floor elements can be used as the basis for a resource-efficient approach to enhance serviceability performance. Full-scale floor elements are positioned in a variety of configurations and then tested for static and dynamic performance using different types of interconnections. Interconnections are mounted both transversally and longitudinally and tied to floor element edge members while varying the number of fasteners. Comfort properties for floor elements are related to damping, but the quantification of damping is challenging. Total damping consists of material damping and structural damping. Whilst material damping may be estimated from the strain energy method (Ungar and Kerwin Jr 1962; Adams and Bacon 1973), the structural damping is difficult to predict because it is linked to detailing in the design and execution of the floor element and its supporting structures (Labonnote et al. 2015). Full-scale tests are therefore an important yet expensive measure to obtain credible values of total damping. To the authors' knowledge, the present study is the only investigation to date addressing interconnections between cassette type timber floor elements.

\section{Materials and methods}

\subsection{Geometry and material properties}

Three closed hollow section (CHS) floor elements with two different spans are studied: Two identical long floor elements (L) and one short floor element (S). A cross-section of two parallel floor elements viewed in the direction of the span is shown in Fig. 1. The floor element cross-section and material selection was based on studies reported in Nesheim and Malo (2018). Each of the floor elements has a continuous frame of two joists (1) and transverse end beams (2) in $405 \times 140$ GL30c. In the main load carrying direction three field joists (3) in $405 \times 66$ GL28c are fitted between the end beams. The cavities are filled with gravel 


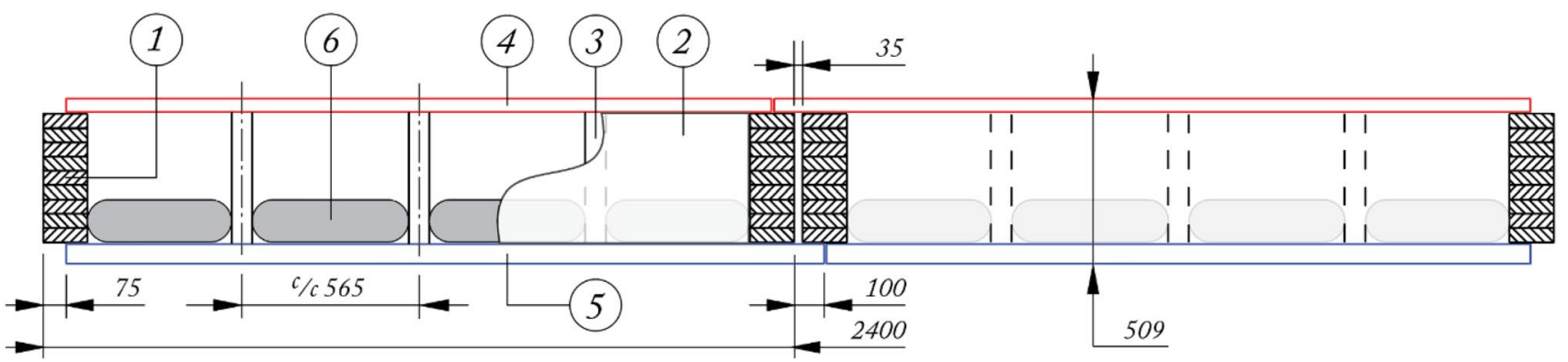

Fig. 1 Floor element cross-section (configuration 3)

type 8/16 (6) with mass corresponding to a distributed $100 \mathrm{~kg} / \mathrm{m}^{2}$ for improved acoustic performance. The floor has a continuous top (4) and bottom (5) flange of 43 and $61 \mathrm{~mm}$ Kerto-Q, respectively. The frame including field joists is both glued and screwed with liquid gap filling phenol-resorcinol adhesive (Dynea 2017) and self-tapping double threaded fastener (SFS WT-T $8.2 \times 220$ ), whilst the flanges were structurally glued together with the same adhesive, but without fasteners. When floor elements are combined laterally, they are referred to as flooring system, and in the current study, the flooring system is simplified and arranged as two elements either in parallel or series. The floor elements of the Woodsol building system is an inherent structural component in the moment resisting frames (MRF), joined to the columns with moment resisting connectors (MRC). In the current study the columns were $405 \times 450$ GL30c, stretching $450 \mathrm{~mm}$ in the direction of the span. The MRC consisted of two parts connected with M30 grade 12.9 friction bolts with a rated tightening torque of $2.5 \mathrm{kNm}$. The parts of the MRC are connected by threaded rods to the floor element edge joists, and columns. See dashed lines to the right of Fig. 2. The length of the MRC was $285 \mathrm{~mm}$ in the direction of span. The long elements (L) were $4.7 \mathrm{~m}$ between end supports, designed at half the span of a typical floor element for the Woodsol building system (Stamatopoulos and Malo 2018), while the short floor (S) was $3.8 \mathrm{~m}$ long. The corresponding system lengths (centre of columns) was 5.72 and $4.82 \mathrm{~m}$. The length of the floor elements and the quantity of internal mass was based on assessments related to acoustic testing (Conta and Homb 2020).

\subsection{Test specimen configurations}

At floor level each face of a column can accommodate one MRC, hence parallel floors share an MRC, whilst elements in series are connected to separate MRC. Principally, the floor element is suspended as illustrated in Fig. 2, and the MRC is represented by a set of normal springs with various stiffness in the cartesian directions. In Fig. 2, the X-direction spring $\left(D_{1}\right)$ is visible. The columns are supported on hinges with no rotational stiffness about the Y-axis. In the test, the floor elements were mounted with the bottom of construction levelled $2 \mathrm{~m}$ above ground. Details on the MRC can be found in Vilguts et al. (2018).

Four different configurations of floor elements were tested. Configuration one through three have floor elements in parallel, whilst configuration four has floor elements in series (see Figs. 3 and 4, respectively).

When floor elements are mounted in parallel, the flooring system differs only by the type of interconnection between the elements. Figure 5 shows the three different connections used for floor elements in parallel.

In configuration $1(\mathrm{C} 1)$, there are no interconnections between elements, and the elements are structurally related only through common columns. In configuration 2 (C2), a section similar to the upper and lower flange is attached between adjacent longitudinal edge joists with a number of screws, and in configuration 3 (C3), the top and bottom
Fig. 2 Spring arrangement for deck in longitudinal direction (left: principle of MRC, right: physical realization)

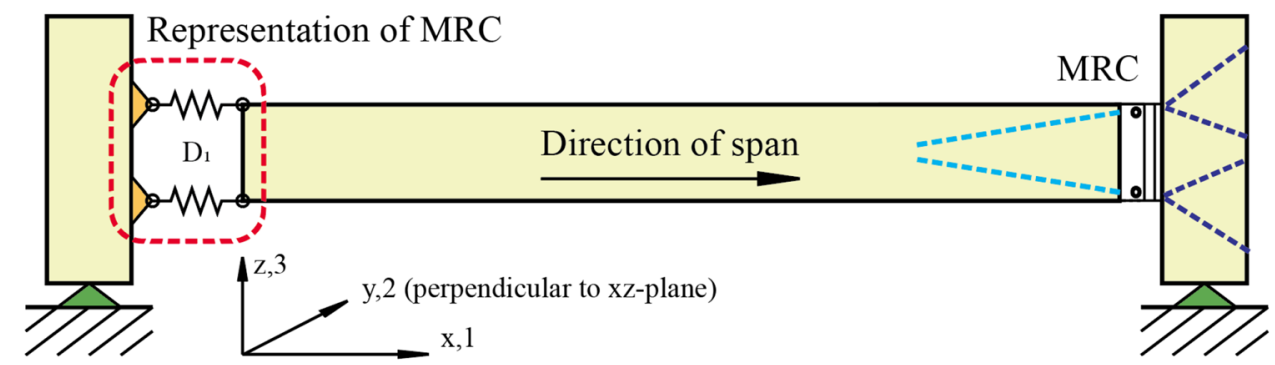


Fig. 3 Plan of configuration 1 through 3 (floor elements in parallel)
Fig. 4 Plan of configuration 4 (floor elements in series)

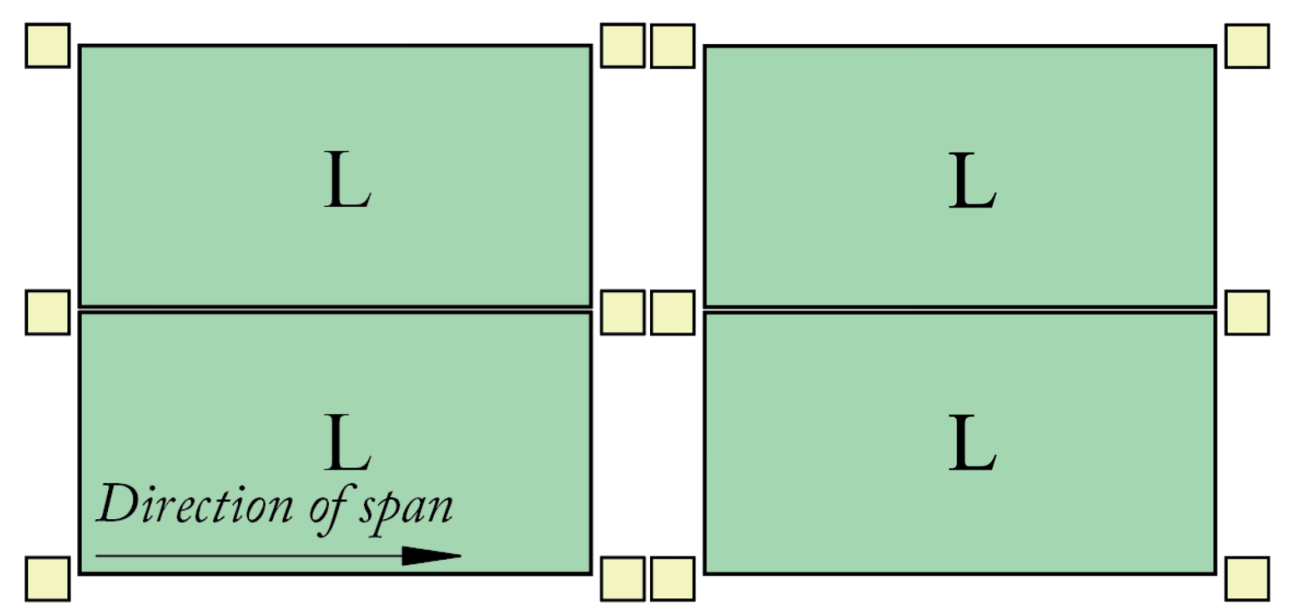

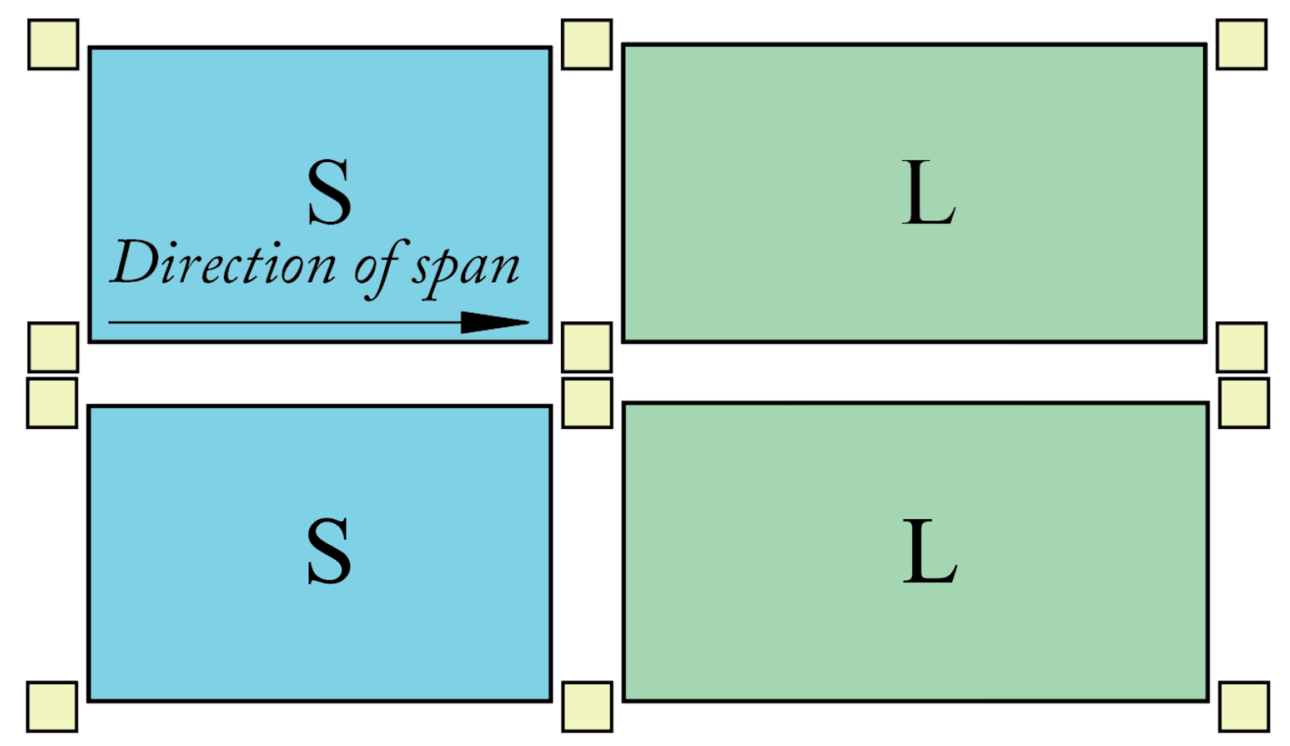

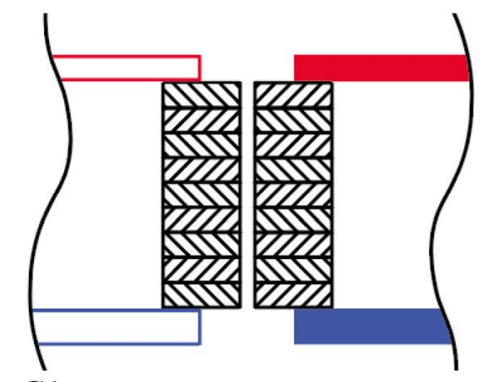

C1

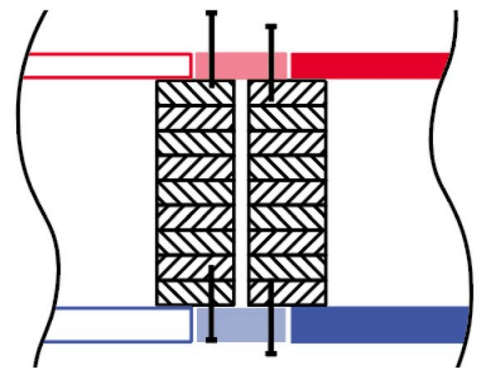

$\mathrm{C} 2$ (principally related to $\mathrm{C} 4$ )

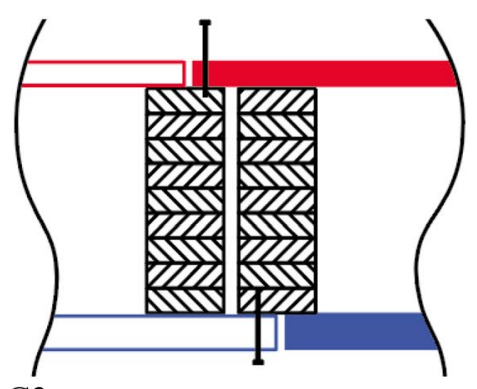

C3

Fig. 5 Section view (in the direction of span) of element interconnections: C1: No connection, C2: Board/bridge connection with twin row of fasteners at top and bottom level, C3: Intersecting connection with single row of fasteners at both levels

flange is respectively extended and retracted to facilitate an intersecting connection with the flanges of the adjacent floor element. The torque on the bolts of the MRC is affecting the rotational stiffness between column and floor element. Configurations $\mathrm{C} 1$ and $\mathrm{C} 2$ are tested with rated torque on the bolts of the MRC. Because the rated tightening torque of the M30 bolts requires hydraulic torque tools, 


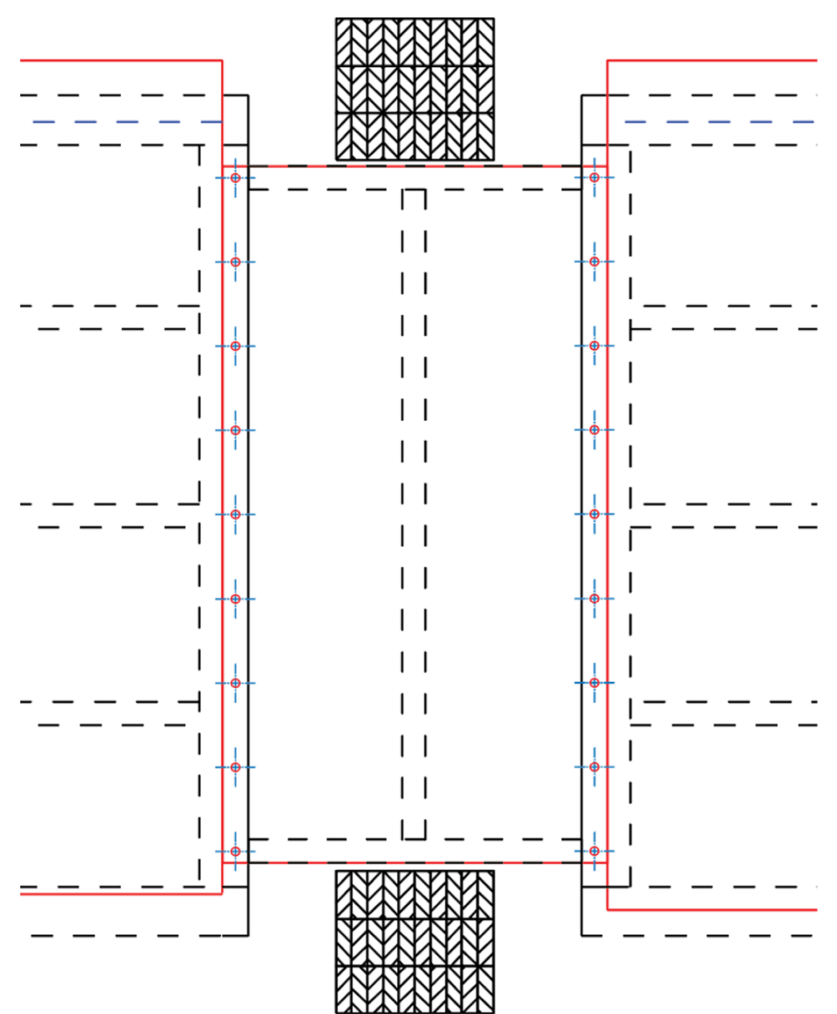

Fig. 6 Fasteners C4 (9 screws at each row and level)

the bolts of the MRC were tightened to $1 \mathrm{kNm}$ achievable by manual labour for the reminder of the tests.

In configuration 4 (C4), floor element $S$ is mounted in series with element $\mathrm{L}$. The $\mathrm{C} 4$ test sequence starts with floor elements connected only through their common columns, advancing with the installation of a bridging component mounted as a transverse interconnection between the floor elements, principally like $\mathrm{C} 2$, but with shear capacity. The bridging component covers the open space caused by the columns and the required space of the MRC (see Fig. 6).
The bridging component is constructed from a central transverse web and two longitudinal edge webs all in GL28c $66 \times 405 \mathrm{~mm}$. The flange plates are identical to the flanges of the floor elements. The bridge piece was not filled with additional mass.

The pattern of fasteners is chosen from combined considerations of required edge spacing, a desired fastener at mid span, even centre to centre distance, and allowance for systematic increase in the number of fasteners. For $\mathrm{C} 2$ and C3, fasteners were positioned according to Figs. 7 and 8, and for $\mathrm{C} 4$ according to Fig. 6. For $\mathrm{C} 2$, the minimum number of fasteners was three per row, at two rows per board. For C3 and $\mathrm{C} 4$, the minimum number was one fastener per row. The sequence of fastening was: one central screw when applicable, three fasteners by adding one screw at each end of the row. Further fastening was then achieved by adding screws between existing screws.

The screw pattern distance was $245 \mathrm{~mm}$ for longitudinal interconnections (C2 and C3), and $240 \mathrm{~mm}$ for transverse interconnection (C4). The fastener used was a partial threaded flange head $\varnothing 8 \mathrm{~mm}$ by $160 \mathrm{~mm}$ for top flange, and $180 \mathrm{~mm}$ for the bottom flange (SFS-HT-T-FH-PT). The nail plate used in C4 was a Rothoblaas LBV $2.0 \times 1200 \times 100$ mounted in series to cover the width of the bridge. Rows of 50 screws per meter were mounted at each longitudinal edge of the nail plate.

\subsection{Design of experiments}

The design of experiments is presented in Tables 1 and 2 . Both tables follow the same setup: ID column are configuration identifiers separated by a running number. Interconnection columns contain number of screws per row, and an additional parameter specifying the particulars of the interconnection: For floor elements in parallel stating the MRC torque, and for floor elements in series stating whether nail plates are used. For $\mathrm{C} 4$ top and bottom flange fastening has
Fig. 7 Fasteners position for C2 (19 screws at each row and level)

Fig. 8 Fasteners position for $\mathrm{C} 3$ (19 screws at each level)
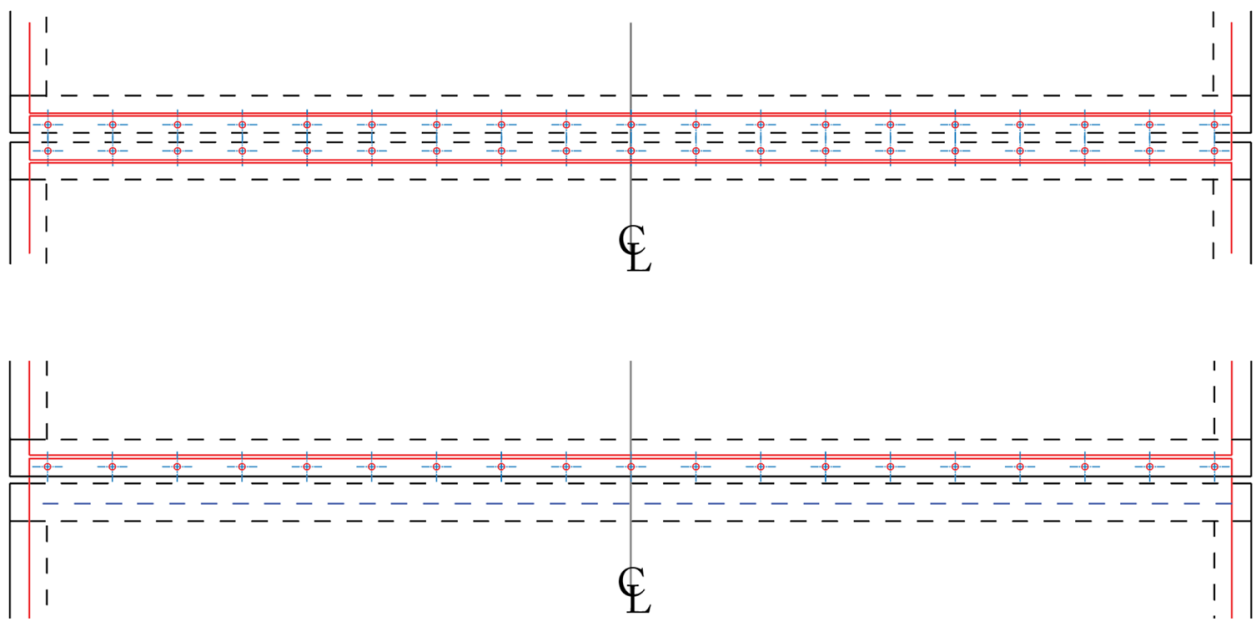
Table 1 Test sequence of floor elements in parallel

\begin{tabular}{|c|c|c|c|c|c|c|}
\hline L & \multirow[b]{2}{*}{ ID } & \multicolumn{2}{|c|}{ Interconnection } & \multirow{2}{*}{$\begin{array}{l}\text { Static } \\
\text { point } \\
\text { load }\end{array}$} & \multirow[b]{2}{*}{$\mathrm{EMV}^{1)}$} & \multirow{2}{*}{$\begin{array}{l}\text { Rowing } \\
\text { hammer }\end{array}$} \\
\hline s & & Screw & $\begin{array}{l}\text { Torque } \\
{[\mathrm{kNm}]}\end{array}$ & & & \\
\hline & c1_0 & 0 & \multirow{2}{*}{2.5} & $\checkmark$ & $\checkmark$ & $\checkmark$ \\
\hline & c1_1 & 0 & & $\checkmark$ & $\checkmark$ & \\
\hline 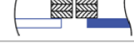 & c1_2 & 0 & \multirow{4}{*}{1.0} & $\checkmark$ & $\checkmark$ & \\
\hline \multirow{6}{*}{ ( } & c2_o & 3 & & $\checkmark$ & $\checkmark$ & \\
\hline & $\mathrm{c} 2 \_1$ & 5 & & $\checkmark$ & $\checkmark$ & \\
\hline & c2_2 & 9 & & $\checkmark$ & $\checkmark$ & \\
\hline & c2 3 & 19 & \multirow{2}{*}{2.5} & $\checkmark$ & $\checkmark$ & $\checkmark$ \\
\hline & c2_ 4 & 19 & & $\checkmark$ & $\checkmark$ & \\
\hline & c2 5 & 19 & \multirow{7}{*}{1.0} & $\checkmark$ & $\checkmark$ & \\
\hline \multirow{6}{*}{ ( } & c3_0 & 0 & & $\checkmark$ & $\checkmark$ & \\
\hline & c3_1 & 1 & & $\checkmark$ & & \\
\hline & c3 2 & 3 & & $\checkmark$ & & \\
\hline & c3_3 & 5 & & $\checkmark$ & & \\
\hline & c3_4 & 9 & & $\checkmark$ & & \\
\hline & c3 5 & 19 & & $\checkmark$ & $\checkmark$ & \\
\hline
\end{tabular}

Table 2 Test sequence of floor elements in series

\begin{tabular}{|c|c|c|c|c|c|c|c|c|c|}
\hline \multirow[b]{3}{*}{$\mathrm{s}$} & \multirow{3}{*}{$\frac{\mathrm{L}}{\mathrm{L}}$} & \multirow{3}{*}{ ID } & \multicolumn{4}{|c|}{ Interconnection } & \multirow{3}{*}{$\begin{array}{l}\text { Static } \\
\text { point } \\
\text { load }\end{array}$} & \multirow{3}{*}{ EMV } & \multirow{3}{*}{$\begin{array}{l}\text { Rowing } \\
\text { hammer }\end{array}$} \\
\hline & & & \multicolumn{2}{|c|}{ Screw } & \multicolumn{2}{|c|}{ Nailplate } & & & \\
\hline & & & Top & Btm & Top & Btm & & & \\
\hline & & c4_1 & 0 & 0 & No & No & $\checkmark$ & $\checkmark$ & $\checkmark$ \\
\hline & & c4_2 & 1 & 1 & No & No & $\checkmark$ & & \\
\hline & & c4_3 & 3 & 3 & No & No & $\checkmark$ & $\checkmark$ & \\
\hline & & c4_4 & 5 & 5 & No & No & $\checkmark$ & $\checkmark$ & $\checkmark$ \\
\hline & & c4_5 & 9 & 9 & No & No & $\checkmark$ & $\checkmark$ & \\
\hline & & c4 6 & 9 & 9 & Yes & No & $\checkmark$ & $\checkmark$ & \\
\hline & & c4 4 & 9 & 9 & Yes & Yes & $\checkmark$ & $\checkmark$ & $\checkmark$ \\
\hline-7 & & c4_8 & 9 & 0 & Yes & No & $\checkmark$ & $\checkmark$ & $\checkmark$ \\
\hline
\end{tabular}

separate columns. Performed tests are given in the last three columns. The selected tests were designed to study variation in deflection and modal parameters as the interconnection between the floor elements was altered. Due to limitations of time and changing boundary conditions, not all tests were performed for the various configurations and interconnections. As can be seen, only a few rowing hammer tests were performed. For floor element in parallel, rowing hammer tests were performed only for the weakest and strongest connection where the MRC is tightened at rated torque. The shaded area identifies factors used in the statistical analysis of structural response as described in Sect. 2.6.

\subsection{Data collection}

\subsubsection{Weight and moisture content}

Weight of the floor elements was $\mathrm{m}_{\mathrm{L}}=2450 \mathrm{~kg}$ and $\mathrm{m}_{\mathrm{S}}=1865 \mathrm{~kg}$, including additional mass. Weight of the MRC parts was 4 pieces of $18 \mathrm{~kg}$ and the associated threaded rods were 16 pieces of $1.5 \mathrm{~kg}$, in addition to weight of adhesive and fasteners $(\sim 10 \mathrm{~kg})$. Moisture content was $10.5 \%$ for glulam, and $11.0 \%$ for LVL.

\subsubsection{Excitations}

Two dynamic and one static excitation test protocol was designed for the study. Types and positions of sensors and excitation source are given in Electronic Supplementary Material (ESM) Fig. S3-S5.

2.4.2.1 Experimental modal analysis (EMA) Rowing Hammer Method (RHM) was applied to quantify out-of-plane deformation modes and damping. The method assumes linearity and time-invariance to fulfil the Maxwell's reciprocity theorem (Pavelka et al. 2015). The response was measured by a stationary ceramic/quartz impedance accelerometer type 8770 A50 (Kistler 2008), and the excitation by the 8210 sledge (Brüel and Kjær 2012). With a mass of $5.44 \mathrm{~kg}$ and with the soft impact tip it produces a $10 \mathrm{mS}$ duration impulse with a maximum force of $500 \mathrm{~N}$. The excitation grids and position of the accelerometer for the tested configurations are given in ESM Fig. S1, S2 and S5.

2.4.2.2 Cyclic load An eccentric mass vibrator (EMV) (Anco Engineers 2010) was used to excite the floor element dynamically from 5 to $30 \mathrm{~Hz}$ during a 2 min sweep. The EMV was mounted to the floor element through an adaptor 
plate tied to the floor element at mid-point. Two accelerometers monitored the response; one at EMV (applicator) and one at immediate proximity to the centre of the bottom flange (receiver). Both accelerometers were of type 8770A50 (Kistler 2008). In addition to floor accelerations, the exciter frequency was recorded. The force from the exciter varied from 50 to $750 \mathrm{~N}$ depending on frequency. Data were recorded at $1200 \mathrm{~Hz}$. The dynamic loading was produced by four rotating weights on two shafts. The weights counter-rotate to retain a unidirectional force. The magnitude of the dynamic loading is controlled by the eccentricity of the weights. By turning the angles of the weights, the eccentricity can be adjusted from 0 to $100 \%$, corresponding to the range from zero to $0.12 \mathrm{~kg} \cdot \mathrm{m}$. The weights were chosen with $30 \%$ eccentricity.

2.4.2.3 Point load deformation A point load was applied at the centre of the top flange via two $\varnothing 8 \mathrm{~mm}$ tension bars connected to load cell and with the loading located under the floor element. The tension bars were affixed to a $16 \mathrm{~mm}$ steel plate distributing the load to the underlaying $200 \mathrm{~cm}^{2}$ load pad as advised in the timber floors test method EN 16929 (CEN 2018b). Because the cross section of the floor element was designed for twice the span, the standard unit load of $1 \mathrm{kN}$ was increased to $10 \mathrm{kN}$. The point load idled at maximum load for $5 \mathrm{~min}$ to expose creep, before it was released to the unloaded state. The rate of loading and unloading was $62 / 3 \mathrm{~N} / \mathrm{s}$ for floor elements in parallel (loading from water balloon as illustrated in Fig. 9), and 1/3 kN/s for floor elements in series (loading from hoist anchored to ground). The response was sampled at $2 \mathrm{~Hz}$. A $50 \mathrm{kN}$ load cell was used (HBM 2019b), and the displacements were recorded with linear variable differential transformers (LVDT) (HBM 2019a), see Figs. 9 and 10.

\subsection{Numerical representation}

Numerical analysis was performed using Abaqus (Dassault Systèmes 2017). Members of the core were modelled

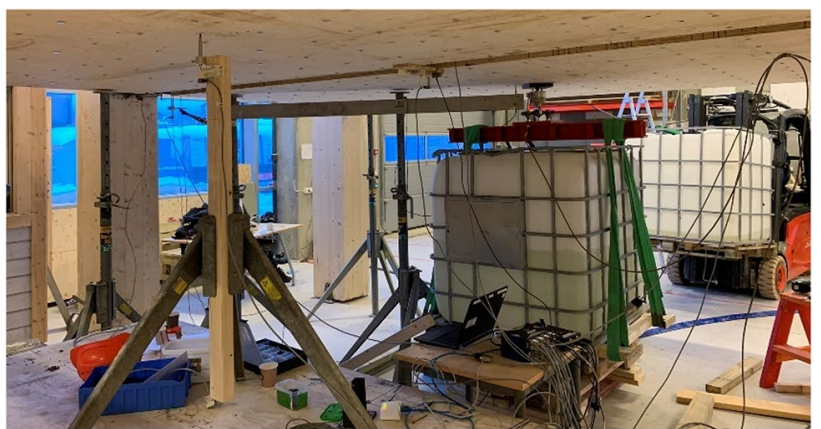

Fig. 10 Static load test situation image

as solids, while shell elements were used for flanges. The interconnections were modelled by shell members tied to the flanges. The representation differs from the study performed in Ebadi et al. (2017), where connecting elements and joists are modelled as simplified 2D quadratic Timoshenko orthotropic element and spring elements for interconnections were used. Particular care was taken for the numerical model to be able to represent accurate eigen frequencies and bending modes, and the selection of elements was done in accordance with Nesheim and Malo (2018). Eight-node brick element (C3D8) was used for all members of the core, whilst four-node shell element (S4) was used for flanges. A surface was put on top and bottom of the floor elements to manage loads and responses. These are modelled with the four-node quadrilateral surface element (SFM3D4). Columns are modelled with solids in C3D8. Each of the four threaded rods of the MRCs was modelled as a linear Cartesian connector with the following properties with respect to the global axis system, where 1 is longitudinal, 2 is transversal and 3 is vertical direction:

$\boldsymbol{D}=\left\{\begin{array}{lll}D_{1} & D_{2} & D_{3}\end{array}\right\}=\left\{\begin{array}{lll}12.2 & 3.7157 .425\end{array}\right\} \cdot 10^{6}\left[\frac{\mathrm{N}}{\mathrm{m}}\right]$.

The modelling did not consider variation in tensioning of the bolts on the MRC, and $\boldsymbol{D}$ was computed to represent a constant rotational stiffness of $2 \mathrm{MNm} / \mathrm{rad}$ between the
Fig. 9 Illustration of load and load cell application

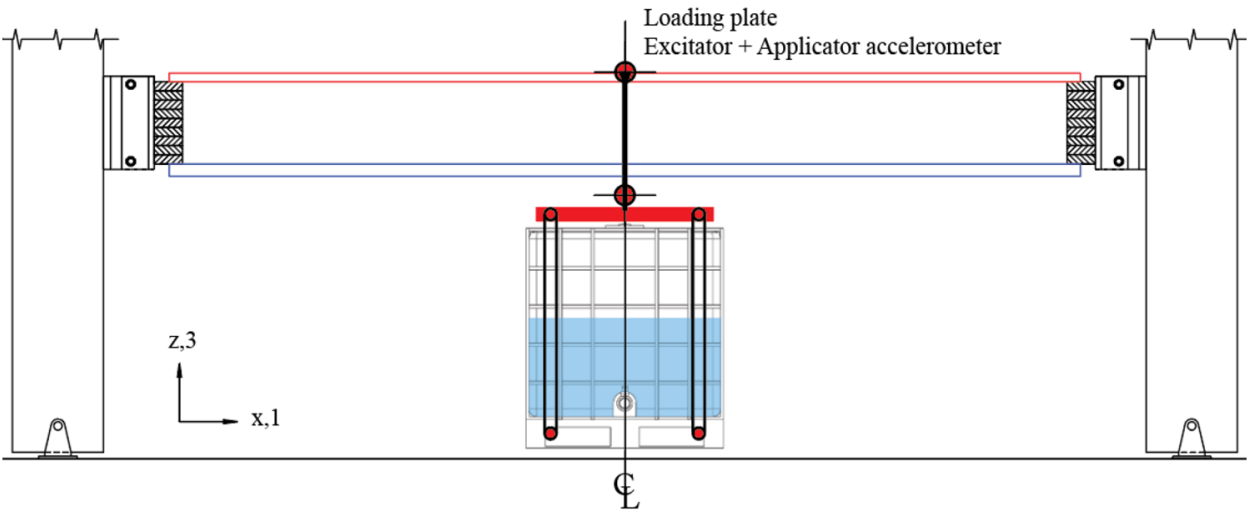


column and each end of the edge joists of the floor element. To allow a realistic force employment from the point loads of the MRC, a reinforced skin modelled as a S4 shell was attached to timber faces covered by the MRC. The skins were all modelled as $27 \mathrm{~mm} \mathrm{S355} \mathrm{steel} \mathrm{plate.} \mathrm{Added} \mathrm{weight}$ of $100 \mathrm{~kg} / \mathrm{m}^{2}$ was applied to the bottom flange to represent internal mass, whilst $15 \mathrm{~kg} / \mathrm{m}^{2}$ was added to top flange to represent adhesive and fasteners.

\subsection{Statistical evaluation}

A statistical evaluation was performed to reveal main effects and the level of significance each factor had on the response of the flooring system. The design of experiment, as explained in Sect. 3.3, was transformed to matrices of factors (columns) and runs (rows) corresponding to the shaded area of Tables 1 and 2. The statistical assessment was performed in Minitab. $\mathrm{Hu}$ and Chui (2004) criterion (1) was used to evaluate changes in performance as alterations in the interconnections changed fundamental frequency $\left(f_{1}\right)$ and unit point load deflections $(w)$. Similarly, changes in dynamic responses were evaluated using the expressions for root mean square of acceleration (2) and velocity (3) as described in Abeysekera et al. (2019).

$$
\begin{aligned}
& \frac{\left(\frac{f_{1}}{18.7}\right)^{2.27}}{w}>1 \\
& a_{r m s}=\frac{\alpha \cdot F_{0}}{7 \cdot \zeta \cdot M^{*}}
\end{aligned}
$$

$\alpha$ is the Fourier coefficient $\alpha=e^{-0.4 \cdot f_{1}}, \zeta$ is the modal damping ratio, $\mathrm{F}_{0}$ is the vertical force imposed by walking person $(700 \mathrm{~N}), \mathrm{M}^{*}$ is the modal mass $M^{*}=\frac{m L B}{4}, \mathrm{~m}$ is the mass $(\mathrm{kg})$ of floor per unit area $\left(\mathrm{m}^{2}\right), \mathrm{B}$ is the width of floor $(\mathrm{m}), \mathrm{L}$ is the span of floor $(\mathrm{m})$.

$v_{r m s}=K_{i m p} \cdot \frac{0.7 \cdot I_{m}}{M^{*}+70}\left(0.65-0.01 \cdot f_{1}\right)(1.22-11 \cdot \zeta) \eta$

$\mathrm{K}_{\mathrm{imp}}$ is the higher modes multiplier for transient response $K_{\text {imp }}=\max \left\{\begin{array}{c}0.48\left(\frac{B}{L}\right)\left(\frac{E I_{L}}{E I_{T}}\right)^{0.25}, \mathrm{EI}_{\mathrm{L}} \text { is the Longitudinal } \\ 1\end{array}\right.$ bending stiffness $\left(\mathrm{Nm}^{2} / \mathrm{m}\right), 1_{\mathrm{m}}$ is the Mean modal impulse $l_{m}=\frac{42 \cdot f_{v}^{1.43}}{f_{1}^{1.3}}, \mathrm{EI}_{\mathrm{T}}$ is the Transverse bending stiffness $\left(\mathrm{Nm}^{2} / \mathrm{m}\right)$,

$\mathrm{f}_{\mathrm{w}}$ is the Walking frequency $(\mathrm{Hz})$, $\eta=\left\{\begin{array}{c}1.52-0.55 \cdot K_{\mathrm{imp}} 1.0 \leq K_{\mathrm{imp}} \leq 1.5 \\ 0.69 \text { otherwise }\end{array}\right.$

\section{Results}

\subsection{Numerical analysis}

Eigenfrequencies from finite element analysis (FEA) are presented in Table 3. The first column of the table contains a reference to the images in Table 4 for the associated modal shapes. No differences were made in the numerical representation of floor elements with longitudinal interconnection (C2 and C3), and the numerical representation is of $\mathrm{C} 2$ with 19 screws. The direction of view is arranged to match the

\begin{tabular}{|c|c|c|c|c|}
\hline Table 4 & Boundary condition & & Frequency $[\mathrm{Hz}]$ & Description of mode shape \\
\hline $\mathrm{L}_{1}$ & \multirow[t]{4}{*}{ Single element attached to column through MRC } & $\mathrm{L}$ & 38.83 & 1st transversal (element) \\
\hline $\mathrm{L}_{2}$ & & & 50.36 & 2nd transversal (element) \\
\hline$S_{1}$ & & $\mathrm{~S}$ & 46.21 & 1st transversal (element) \\
\hline $\mathrm{S}_{2}$ & & & 56.86 & 2nd transversal (element) \\
\hline $\mathrm{C}_{1}$ & \multirow{4}{*}{\multicolumn{2}{|c|}{ C1 (uncoupled elements type L) }} & 22.82 & 1st transversal (diaphragm)/RB roll (element) \\
\hline $\mathrm{Cl}_{2}$ & & & 38.87 & 2nd transversal (elements out-of-phase viewed) \\
\hline $\mathrm{C}_{3}$ & & & 50.38 & 3rd transversal \\
\hline $\mathrm{C}_{4}$ & & & 52.06 & 1st torsional \\
\hline $\mathrm{C} 2{ }_{1}$ & \multirow{4}{*}{\multicolumn{2}{|c|}{ C2 19 s (coupled elements type L) }} & 24.61 & 1st transversal (diaphragm) \\
\hline $\mathrm{C} 2_{2}$ & & & 32.72 & 2nd transversal \\
\hline $\mathrm{C} 2_{3}$ & & & 37.7 & 1st torsional \\
\hline $\mathrm{C} 2_{4}$ & & & 39.42 & 3rd transversal \\
\hline $\mathrm{C}_{1}$ & \multirow{4}{*}{\multicolumn{2}{|c|}{$\begin{array}{l}\mathrm{C} 4 \text { ( } \mathrm{L} \text { and } \mathrm{S} \text { in series) modelled as nail plates on top and } \\
\text { bottom }\end{array}$}} & 23.57 & L-dominated 1st torsional (element roll) \\
\hline $\mathrm{C}_{2}$ & & & 29.96 & S-dominated 1st torsional (element roll) \\
\hline $\mathrm{C}_{3}$ & & & 35.15 & 1st longitudinal (L-dominated) \\
\hline $\mathrm{C}_{4}$ & & & 39.36 & L-dominated 1st transversal \\
\hline
\end{tabular}

Table 3 FEA fundamental frequency analyses

The bold/italic is a link between corresponding configurations and modal shapes 
Table 4 FEA fundamental frequency mode shapes

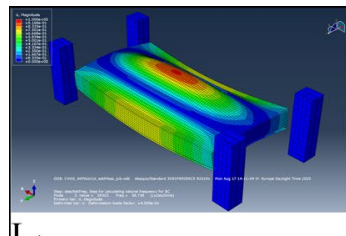

$\mathrm{L}_{1}$

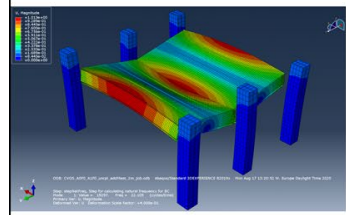

$\mathrm{C}_{1}$

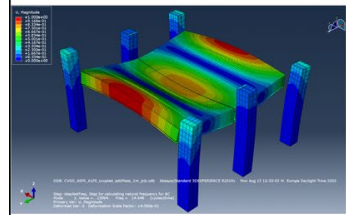

$\mathrm{C} 2{ }_{1}$

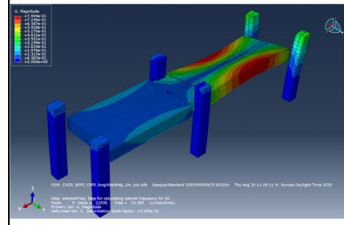

$\mathrm{C}_{1}$

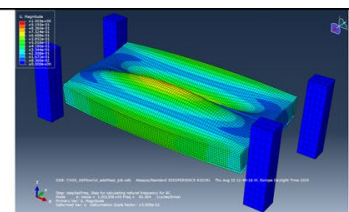

$\mathrm{L}_{2}$

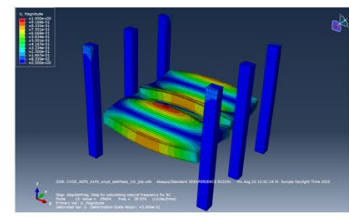

$\mathrm{C}_{2}$

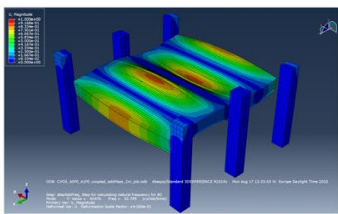

$\mathrm{C} 2{ }_{2}$

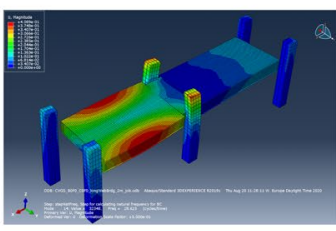

$\mathrm{C}_{2}$

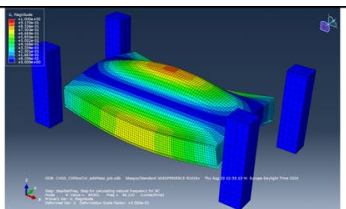

$\mathrm{S}_{1}$

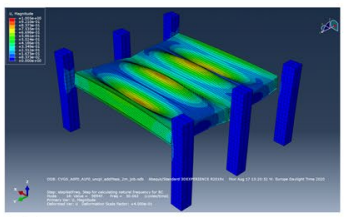

$\mathrm{Cl}_{3}$

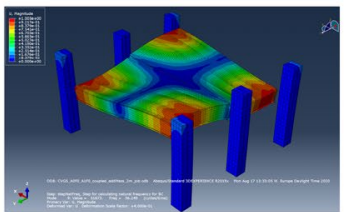

$\mathrm{C} 2{ }_{3}$

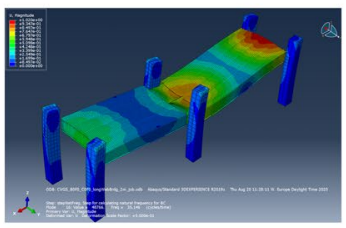

$\mathrm{C}_{3}$

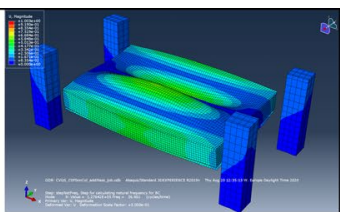

$\mathrm{S}_{2}$

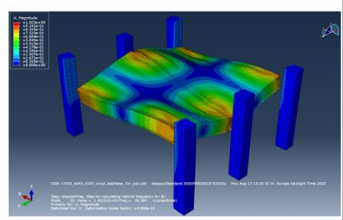

$\mathrm{Cl}_{4}$

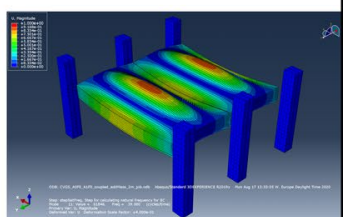

$\mathrm{C} 2{ }_{4}$

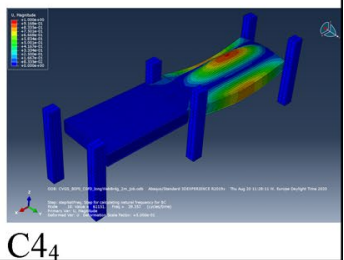

view of corresponding configurations in Table 5. Due to the wide edge joists made to accommodate the threaded rods, the longitudinal bending stiffness $\left(\mathrm{EI}_{\mathrm{L}}\right)$ is higher at the element edges compared to the field. Furthermore, since the bending stiffness transversally $\left(\mathrm{EI}_{\mathrm{T}}\right)$ is low, transverse mode orders dominate the mode shapes, typically in combination with first longitudinal mode of the field of the floor element.

\subsection{Rowing hammer experiments}

Table 5 presents governing mode shapes from 1 to $\mathrm{n}$ with corresponding frequencies $\left(f_{n}\right)$ and damping $\left(\zeta_{n}\right)$ for the flooring system as measured by rowing hammer testing. The grids for the rowing hammer positions are visualized in the ESM Fig. S1 and S2 for floor elements in parallel and series, respectively. Due to the low vertical stiffness of the MRC, rigid body motions were large with respect to modal deformations. Furthermore, since the objective of the present work is focusing at the relative movement between the floor elements, the rigid body motions were excluded (Table 6).

\subsection{Cyclic loading experiments}

Responsive energy characterised by power spectral density (PSD) of accelerations of the floor elements due to imposed dynamic loading is charted in Figs. 11 and 12.

Table 5 EMA frequency and damping results floor elements in parallel

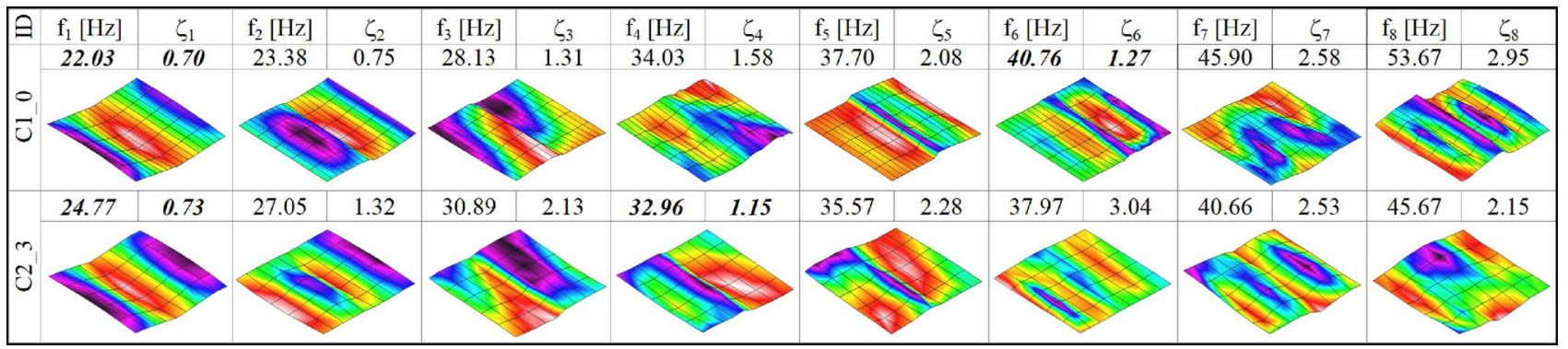

The bold/italic is a link between corresponding configurations and modal shapes 
Table 6 EMA frequency and damping results floor elements in series

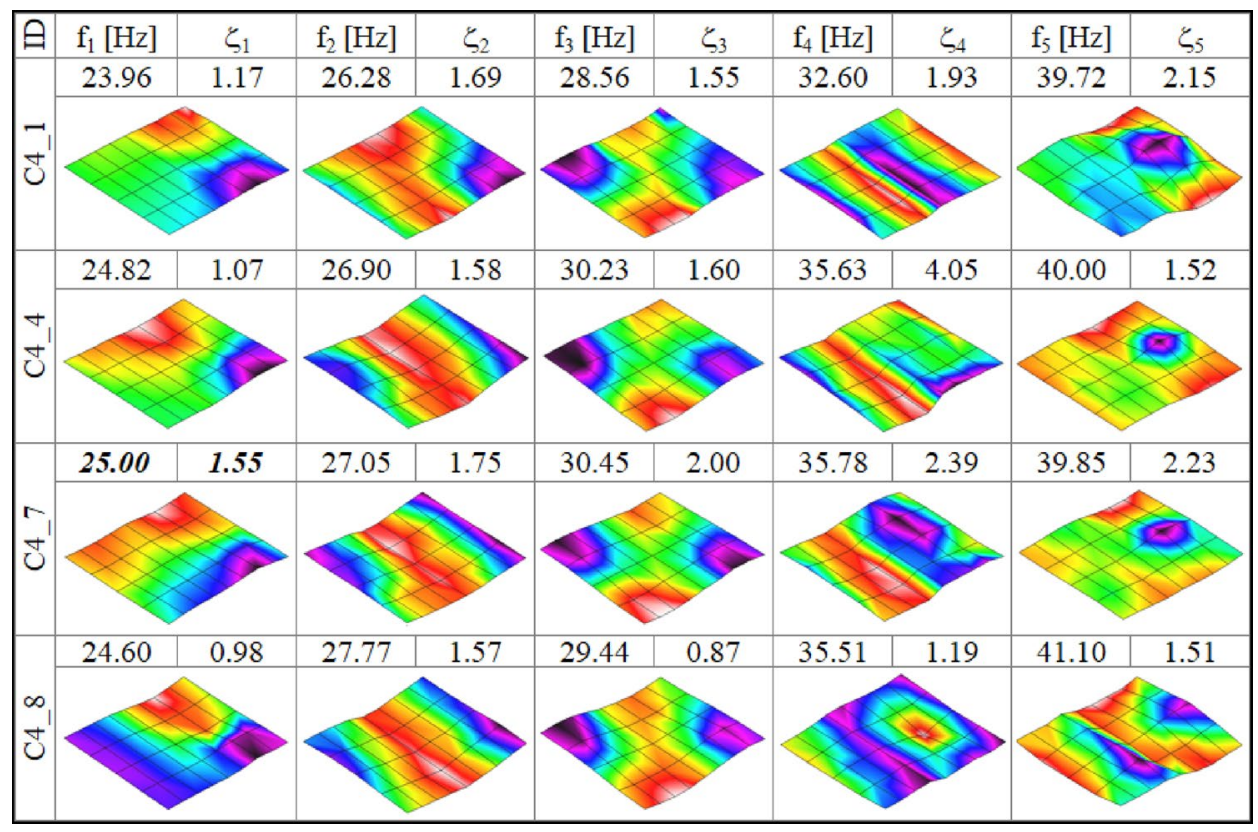

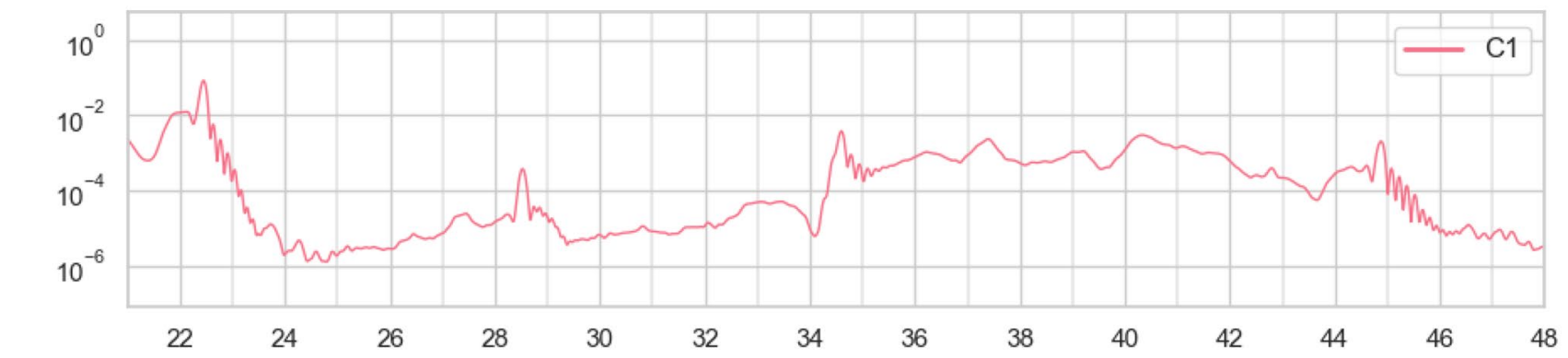
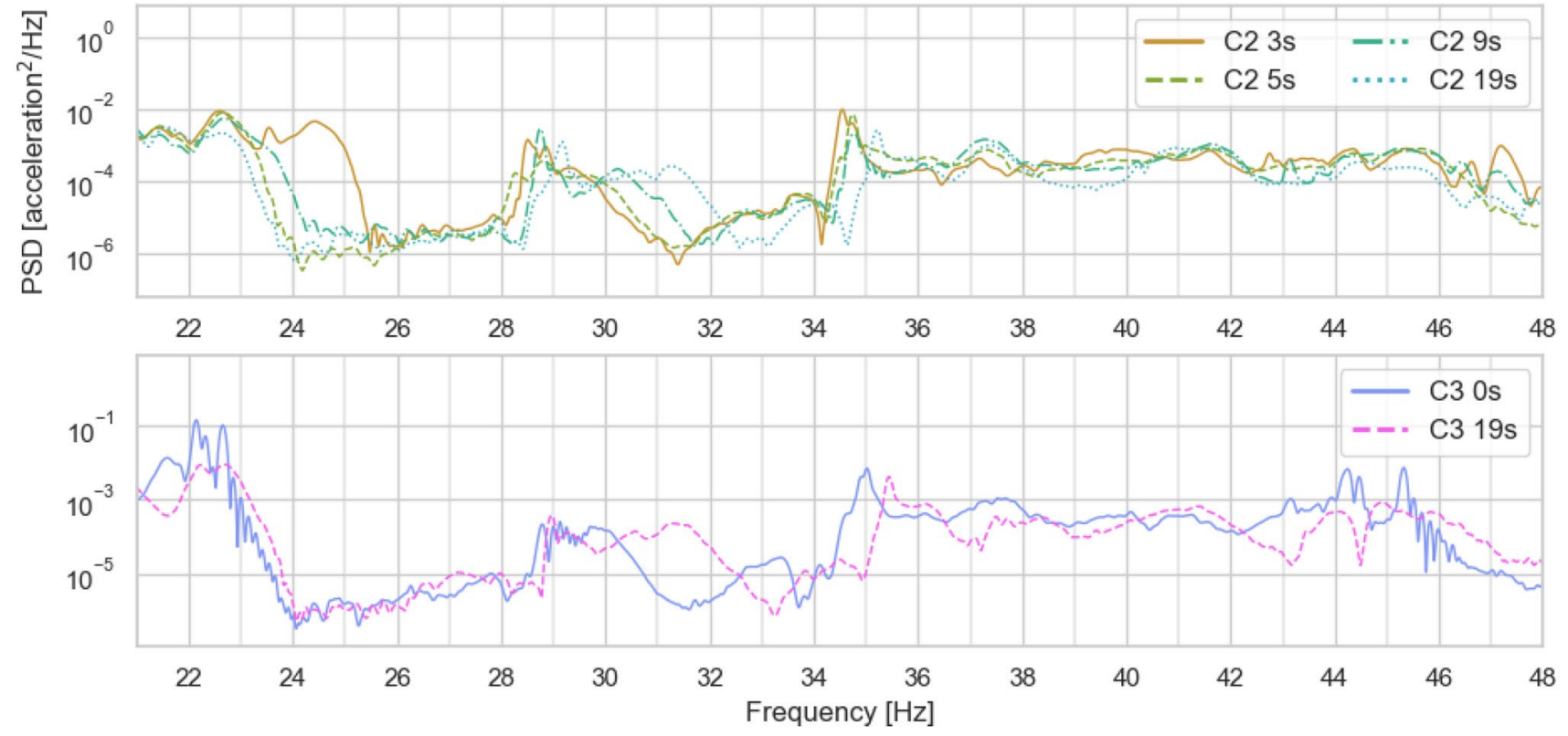

Fig. 11 Logarithmic plot of PSD for responses in configurations 1-3 

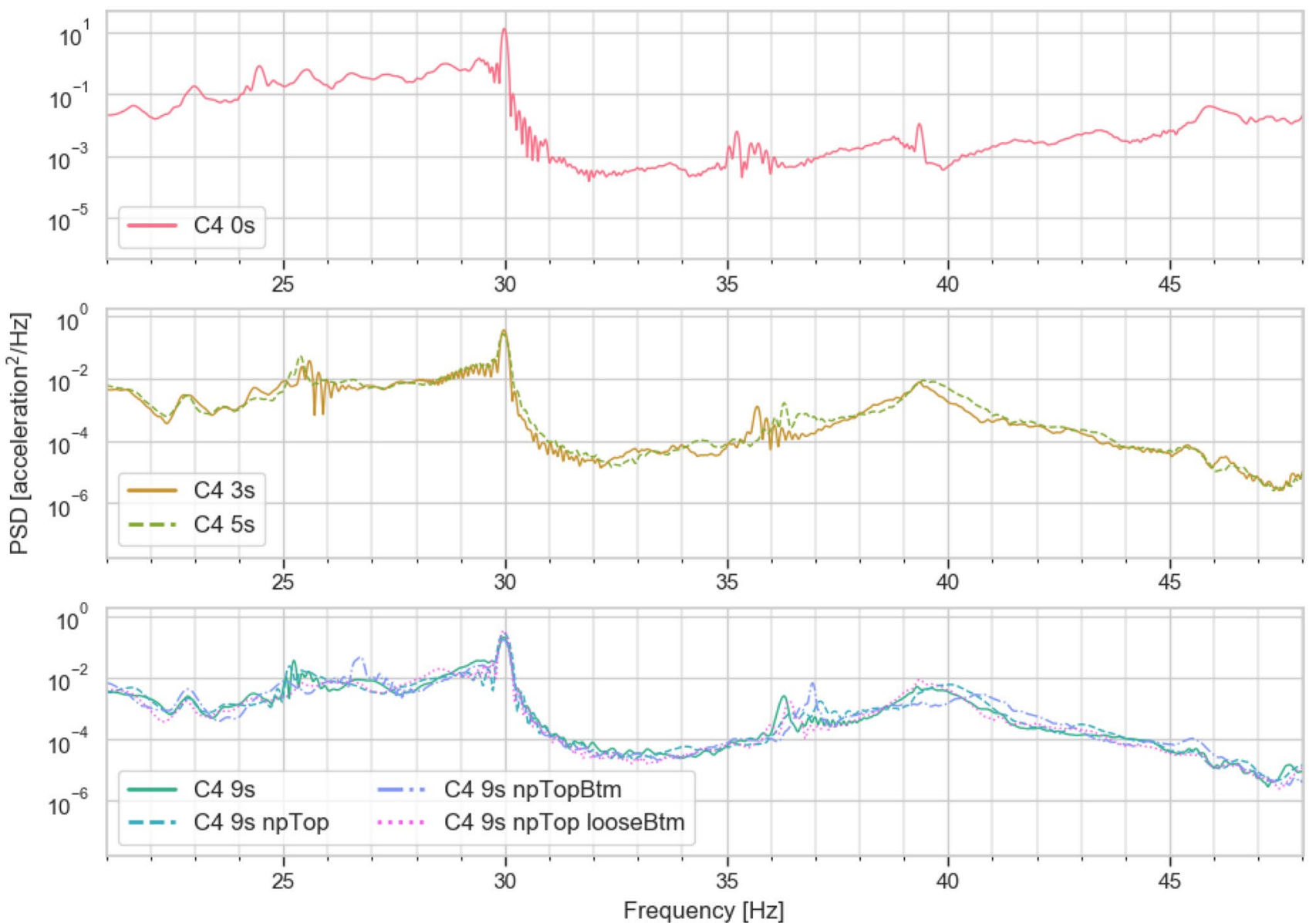

Fig. 12 Logarithmic plot of PSD for responses in configuration 4

Table 7 Dominant resonant peak properties from Welch method

\begin{tabular}{|c|c|c|c|c|c|}
\hline \multirow{2}{*}{ Description } & \multirow[t]{2}{*}{ ID } & \multicolumn{2}{|c|}{ 1st dominant } & \multicolumn{2}{|c|}{ 2nd dominant } \\
\hline & & $\begin{array}{l}\text { Frequency } \\
{[\mathrm{Hz}]}\end{array}$ & $\begin{array}{l}\text { Value } \\
{\left[\left(\mathrm{m} / \mathrm{s}^{2}\right)^{2} / \mathrm{Hz}\right]}\end{array}$ & $\begin{array}{l}\text { Frequency } \\
{[\mathrm{Hz}]}\end{array}$ & $\begin{array}{l}\text { Value } \\
{\left[\left(\mathrm{m} / \mathrm{s}^{2}\right)^{2} / \mathrm{Hz}\right]}\end{array}$ \\
\hline $\mathrm{C} 1$ & c1_2 & 34.60 & 0.0038 & 37.38 & 0.0024 \\
\hline $\mathrm{C} 23 \mathrm{~s}$ & c2_0 & 34.54 & 0.0097 & 37.18 & 0.0005 \\
\hline $\mathrm{C} 25 \mathrm{~s}$ & c2_1 & 34.73 & 0.0072 & 37.44 & 0.0008 \\
\hline $\mathrm{C} 29 \mathrm{~s}$ & c2_2 & 34.78 & 0.0021 & 37.28 & 0.0015 \\
\hline C2 $19 \mathrm{~s}$ & c2_5 & 35.11 & 0.0026 & 37.39 & 0.0010 \\
\hline $\mathrm{C} 30 \mathrm{~s}$ & c3_0 & 35.02 & 0.0071 & 37.52 & 0.0011 \\
\hline C3 $19 \mathrm{~s}$ & c3_5 & 35.44 & 0.0043 & 37.49 & 0.0004 \\
\hline $\mathrm{C} 40 \mathrm{~s}$ & c4_1 & 35.12 & 0.0062 & 39.34 & 0.0180 \\
\hline $\mathrm{C} 43 \mathrm{~s}$ & c4_3 & 35.69 & 0.0013 & 39.35 & 0.0077 \\
\hline $\mathrm{C} 45 \mathrm{~s}$ & c4_4 & 36.30 & 0.0017 & 39.43 & 0.0088 \\
\hline $\mathrm{C} 49 \mathrm{~s}$ & c4_5 & 36.29 & 0.0026 & 39.30 & 0.0052 \\
\hline C4 9 s npTop & c4_6 & 37.11 & 0.0018 & 40.05 & 0.0061 \\
\hline C4 9 s npTopBtm & c4_7 & 36.93 & 0.0068 & 40.79 & 0.0030 \\
\hline C4 9 s npTop looseBtm & c4_8 & 36.42 & 0.0018 & 39.35 & 0.0087 \\
\hline
\end{tabular}


Corresponding peak values are given in Table 7. The magnitude of dynamic loading as generated by the EMV is controlled by the crank weight, eccentricity (set at 30\%), and angular frequency squared as given in Eq. (1).

$F_{E M V}(f)=0.12 \mathrm{kgm} \cdot 30 \% \cdot(2 \pi f)^{2}$.

Responses below $20 \mathrm{~Hz}$ are related to rigid body motions and are disregarded. These are succeeded by modal shapes associated with behaviour of the floor elements, starting with responses for the floor acting as a common diaphragm from 22 to $25 \mathrm{~Hz}$. The vertical motions of the floor elements are mainly caused by deflections in the MRCs, which were large compared to deformations associated with the floor elements. Hence, modal properties of the isolated flooring system were not obvious from a standard FFT-analysis. However, by applying Welch's method (Welch 1967), the modal deformations associated with the flooring system appear distinctly in the PSD charts as seen in Figs. 11 and 12. For $\mathrm{C} 4$, the peaks at $30 \mathrm{~Hz}$ are disregarded. These peaks are associated with resonance in the EMV due to a frequency sweep out of range.

\subsection{Unit load deflection}

As explained in 2.4.2.3, due to assumed linearity the point load was increased to $10 \mathrm{kN}$ to have measurable deformations. Deformations at unit load $(1 \mathrm{kN})$ were then calculated by regression analyses of the measured deformations from the entire loading protocol. $\mathrm{R}^{2}$ were typically above $96 \%$. Relative deflection and root mean square error (RMSE) were calculated for all response parameters and compiled into tables. Tables 8 and 9 contain dimensionless responses as relative deformations with respect to $\mathrm{C} 1 \_\mathrm{A}$ for floor elements in parallel, and to C4_1 for floor elements in series. In ESM Table S1 and S2, RMSE from the regression analyses is found. Only the most relevant measurements are displayed in Tables 8 and 9. Compression of sensors yield positive number.
Table 8 Relative deflection of selected positions with respect to $\mathrm{C} 1 \_\mathrm{A}$
Table 9 Relative deflection of selected positions with respect to $\mathrm{C} 4-1$

\begin{tabular}{lllllllll}
\hline ID & $\begin{array}{l}\text { ZA0 } \\
{[1]}\end{array}$ & $\begin{array}{l}\text { ZA2 } \\
{[1]}\end{array}$ & $\begin{array}{l}\text { ZAmean1and4 } \\
{[1]}\end{array}$ & $\begin{array}{l}\text { ZA5 } \\
{[1]}\end{array}$ & $\begin{array}{l}\text { ZA6 } \\
{[1]}\end{array}$ & $\begin{array}{l}\text { ZR0 } \\
{[1]}\end{array}$ & $\begin{array}{l}\text { RYatCon } \\
{[1]}\end{array}$ & $\begin{array}{l}\text { RXbtwFlr } \\
{[1]}\end{array}$ \\
\hline c1_A & 1 & 1 & 1 & 1 & 1 & 1 & 1 & 1 \\
c1_2 & 1.062 & 1.353 & 1.168 & 0.733 & 1.057 & 1.156 & 0.059 & Invalid \\
c2_0 & 1.062 & 1.096 & 1.108 & 0.728 & 0.980 & 0.582 & -2.154 & 1.386 \\
c2_1 & 1.025 & 1.208 & 1.035 & 0.721 & 0.983 & 0.475 & -2.776 & 1.128 \\
c2_2 & 1.016 & 1.092 & 1.018 & 0.703 & 0.976 & 0.316 & -0.861 & 2.056 \\
c2_A & 0.976 & 1.189 & 0.858 & 0.959 & 0.984 & 0.017 & -0.545 & 2.129 \\
c2_5 & 1.038 & 1.129 & 0.990 & 0.697 & 0.983 & 0.126 & -2.102 & 2.353 \\
c3_0 & 0.800 & 1.099 & 0.986 & 0.861 & 1.000 & 0.551 & -0.809 & 0.326 \\
c3_1 & 0.952 & 1.328 & 0.815 & 0.881 & 1.024 & 0.254 & -0.212 & 0.644 \\
c3_2 & 0.868 & 1.060 & 0.800 & 0.834 & 1.014 & 0.063 & -1.415 & 0.766 \\
c3_3 & 0.880 & 1.325 & 0.918 & 0.869 & 1.023 & 0.116 & -0.665 & 0.822 \\
c3_4 & 0.913 & 1.270 & 0.797 & 0.849 & 1.031 & 0.000 & -1.258 & 1.214 \\
c3_5 & 0.878 & 1.399 & 0.880 & 0.879 & 1.022 & 0.000 & -1.215 & 1.814 \\
\hline
\end{tabular}

\begin{tabular}{lllllllll}
\hline ID & $\begin{array}{l}\text { ZAmean0and4 } \\
{[1]}\end{array}$ & $\begin{array}{l}\text { ZA1 } \\
{[1]}\end{array}$ & $\begin{array}{l}\text { ZA2 } \\
{[1]}\end{array}$ & $\begin{array}{l}\text { ZAmean3and9 } \\
{[1]}\end{array}$ & $\begin{array}{l}\text { ZA5 } \\
{[1]}\end{array}$ & $\begin{array}{l}\text { ZA6 } \\
{[1]}\end{array}$ & $\begin{array}{l}\text { ZAmean7and8 } \\
{[1]}\end{array}$ & $\begin{array}{l}\text { RYbtwFlr } \\
{[1]}\end{array}$ \\
\hline c4_1 & 1 & 1 & 1 & 1 & 1 & 1 & 1 & 1 \\
c4_2 & 0.991 & 1.043 & 1.194 & 1.039 & 0.991 & 0.991 & 1.107 & 0.995 \\
c4_3 & 0.986 & 2.753 & 2.249 & 0.961 & 0.997 & 1.021 & 3.740 & 0.801 \\
c4_4 & 0.961 & 2.912 & 2.857 & 0.957 & 0.976 & 1.009 & 3.993 & 0.826 \\
c4_5 & 0.971 & 2.969 & 2.288 & 0.943 & 0.983 & 1.026 & 4.392 & 0.718 \\
c4_6 & 0.906 & 3.704 & 2.593 & 0.888 & 0.922 & 0.996 & 5.521 & 0.452 \\
c4_7 & 0.823 & 4.210 & 3.099 & 0.992 & 0.927 & 1.004 & 8.078 & -0.066 \\
c4_8 & 0.841 & 3.153 & 2.516 & 0.996 & 0.949 & 1.018 & 5.355 & 0.938 \\
\hline
\end{tabular}




\subsection{Floor elements in parallel}

The reference denoted $\mathrm{C} 1 \_\mathrm{A}$ is the average structural responses of C1_0 and C1_1. Similarly, C2_3 and C2_4 are replaced with an average C2_A. C1_A and C2_A are the tests where the friction bolts of the MRC are tightened at rated pre-stressing torque $(2.5 \mathrm{kNm})$. Note that ZAmeanland4 is the mean value of ZA1 and ZA4. RYatCon and $R X b t w F l r$ are respectively relative rotation in radians about Y-axis between column and edge of floor element, and relative rotation about $\mathrm{X}$-axis between longitudinal adjacent floor elements.

\subsubsection{Floor elements in series}

Note that ZAmeanOand4, ZAmean3and9 and ZAmean7and8 is the mean value of ZA0 and ZA4, ZA3 and ZA9, and ZA7 and ZA8, respectively. RYbtwFlr is the relative rotation in radians about Y-axis between the two end beams (transversal part of floor element frame) facing the bridging component.

\subsection{Statistical assessment}

A full factorial analysis was generated based on the dimensionless responses from the point load. The included terms in the model were seven terms for floor elements in parallel (three factors: See shaded columns of Table 1), and 15 for floor elements in series (four factors: See shaded columns of Table 2). Two-sided confidence level for all intervals was set to $95 \%$. Data from the analyses was exposed in three charts:

1. Pareto chart to express the absolute values of standardized effects in ascending order aiding to determine the magnitude and importance of the effects of the factor. The reference line in the chart indicates the statistically significant factor at a given significance level.

2. Main effect chart to show how the fluctuation in mean response as the level of a factor moves between its extremes.

3. Interaction chart to express the relationship between one factor and the continuous response depending on the value of a second factor. An interaction implies that the response due to one factor depends on the level of the other factor.

These charts are the results of the analysis, and the charts are used in the discussion. The charts are given in ESM.

\section{Discussion}

\subsection{Comparison of dynamic responses}

The most significant effect of tying the floor elements together is the advancing formation of modal shapes where the elements are responding as a common diaphragm. In mode shapes where energy is dissipated in the interconnection, structural damping is increasing, and frequency is shifted depending on the direction of the mode and the mode order. Mode interactions are complicating the interpretation. To assist in the assessment of the influence of interconnection, the responsive energy is therefore examined: The power intensity of the accelerations as a function of frequency, as described by the PSD, reveals information on how the flooring system is responding at a given frequency band by assessing the amplitude and width of peaks. The influence on human perception of vibration is in the present work evaluated from a combined examination of shift in frequency, damping and responsive energy, and the floor elements in parallel and in series are discussed separately. In the discussion, reference to mode shapes is made with respect to Tables 5 and 6. Interpretation of the PSD are challenging because the peaks are separated with nearly equal spacing, indicating that the peaks can be associated with harmonic components of the same mode. Furthermore, the frequency range of the EMV was not high enough to actively stimulate the vibrations of interest, and the analysis was trusting random vibrations of higher harmonics to be developed by the vibration source.

For both floors in parallel and in series, the effect of tying floor elements together is characterized in the PSD as a flattening of the resonant energy. This has the effect of reducing the susceptibility of fundamental frequencies responding as a distinct peak, making the flooring system less disposed to resonance from a single frequency source. The peaks tend to agree with fundamental mode orders starting with transverse mode.

\subsubsection{Floor elements in parallel}

The longitudinal interconnection constrains relative movements between floor elements, and depending on the mode shape, the interconnection will be subjected to axial and shear stresses. For modal deformations longitudinally, the effect of the interconnection on bending stiffness is neglectable, and it is evident that the modal mass increases with respect to the bending stiffness causing a reduction in frequency. This mechanism is reflected in the numerical analyses where eigen frequencies for first common mode decrease with $15.8 \%$. This is also demonstrated in the experimental results where eigen frequencies from EMA 
suggest a decrease by $19.1 \%$ from $\mathrm{f}_{6, \mathrm{C} 1 \_0}(40.8 \mathrm{~Hz})$ to $\mathrm{f}_{4, \mathrm{C} 2 \_3}$ $(33.0 \mathrm{~Hz})$ for modes dominated by longitudinal deformations. This interpretation supports findings in Ebadi et al. (2016) and Ebadi (2017). No significant change in damping was observed for this mode.

For transverse mode shapes the trend is different: The increase in bending stiffness of the flooring system caused by the interconnection is significant with respect to the limited bending stiffness the floor element has transversally. From uncoupled to coupled elements (C2_3), the numerical analysis yields a shift in eigenfrequency for first transversal mode upwards from $22.8 \mathrm{~Hz}$ to $24.6 \mathrm{~Hz}$ (7.9\%), comparable to the EMA which changes from $22.0 \mathrm{~Hz}$ for $\mathrm{f}_{1, \mathrm{Cl}_{-} 0}$ to $24.8 \mathrm{~Hz}$ for $\mathrm{f}_{1, \mathrm{C}_{2} 3}(12.4 \%)$. For this mode for C2_3, the interconnection is activated in-plane and perpendicular to the length of the interconnection, and the axial stress causes no significant change in damping.

For the second transversal mode $\left(\mathrm{f}_{2}\right)$, the interconnection is activated for shear stress perpendicular to plane and the damping ratio is increased from $0.75 \%$ to $1.32 \%$. As can be seen from comparing the matching first two transversal modes $\left(\mathrm{f}_{1}\right.$ and $\mathrm{f}_{2}$ ) of $\mathrm{C} 1 \_0$ and $\mathrm{C} 2 \_3$, it is evident that the shift is attributed to structural damping in the interconnection. Shear deformation of both the interconnector and the floor elements generally renders high damping. This supports the findings in Labonnote et al. (2013).

Advancing to $\mathrm{f} 3$, torsion of the floor elements is causing shear dominant stresses, and the damping of C1_0 where there is no interconnection, is also generating high damping. When tying the floor elements together, the same mode is seen in $\mathrm{f}_{3, \mathrm{C}_{2} 3}$, and structural damping from the shear stressed connection is increasing the total damping from 1.31 to $2.13 \%$ as system boundaries alter. The torsional modes are however significantly stimulated by the low vertical stiffness of the MRC and would undoubtedly be less evident if the vertical motion of the floor element supports was more constrained.

In mode order five, the damping is high for both configurations: For C1_0, the mode is the second transverse mode. The damping is higher than for the first transverse mode, and lower than for the third transverse mode $\left(\mathrm{f}_{8, \mathrm{C} 1_{0}}\right)$, strengthening the finding of increased damping for increasing mode order, supporting the findings in Labonnote et al. (2013).

For floor elements in parallel, as stiffness in the interconnection is increased, the frequency spacing between adjacent modes decreases, supporting findings in Ebadi et al. (2016).

\subsubsection{Floor elements in series}

Due to the geometry and the support conditions, the interconnection is only subject to axial stresses, and shear due to bending from connected floor elements. Shear stresses from deflection is predominantly transferred to the columns. The bridging component requires both top and bottom flange to be connected to increase the bending stiffness of the flooring system. This is observed in the EMA particularly for C4_1 (loose bridge) from which the frequency is slightly increasing with increasing stiffness of the bridging component. However, no significant interaction was observed between frequency spacing of adjacent modes and stiffness of the interconnection.

For 1st transverse (f1), longitudinal (f2) and transverse (f3), as well as for 2 nd transverse (f5), increasing stiffness generally causes higher damping.

The damping tends to be higher with nail plates than with a number of larger screws, even as the screwed connection is causing a comparable shift in frequency, hence arguing a comparable increase in bending stiffness. The exception from this tendency is seen in the 2 nd longitudinal mode where high damping already is found in the loose bridge $\left(f_{4, C 4 \_}\right)$, and increasing from 1.93 to $4.05 \%$ with a screwed connection, whilst it only increases slightly with nail plates. This is difficult to explain, but this is the only mode shape where the curvature is changing direction across the bridging component, and shear stress is predominantly transferred to the columns.

For the last EMA test, the bridging component is fastened with nail plates at the top flange, but the bottom flange is loose. This test was performed because it represents a favourable method of installing and fastening the bridging component. However, the performance of the flooring system is unfortunate, and damping is generally low. In comparison, even a completely loose bridging component tends to cause higher damping.

\subsection{Point load deflection}

The following discussion is based on statistical analyses of the deflection tests as described in Sect. 1.2. The charts used as background for the discussion are found in ESM.

\subsubsection{Floor elements in parallel}

The propagation of deflection from loaded to unloaded floor element increases by up to $30 \%$ as the interconnection gains stiffness. (Fig. S6) (RMSE considered). The Pareto chart shows significance for type of configuration and torque of MRC bolts (Fig. S7). Main effects clearly state that the C3 interconnection is the most effective connection to even out deflection between floor elements. For rated prestressing torque, response of unloaded floor tends to increase from configuration $1-2$, whilst for $1.0 \mathrm{kNm}$ torque, the same response tends to decrease from configuration 1 . Not immediately expected, this indicates that the deflection of 

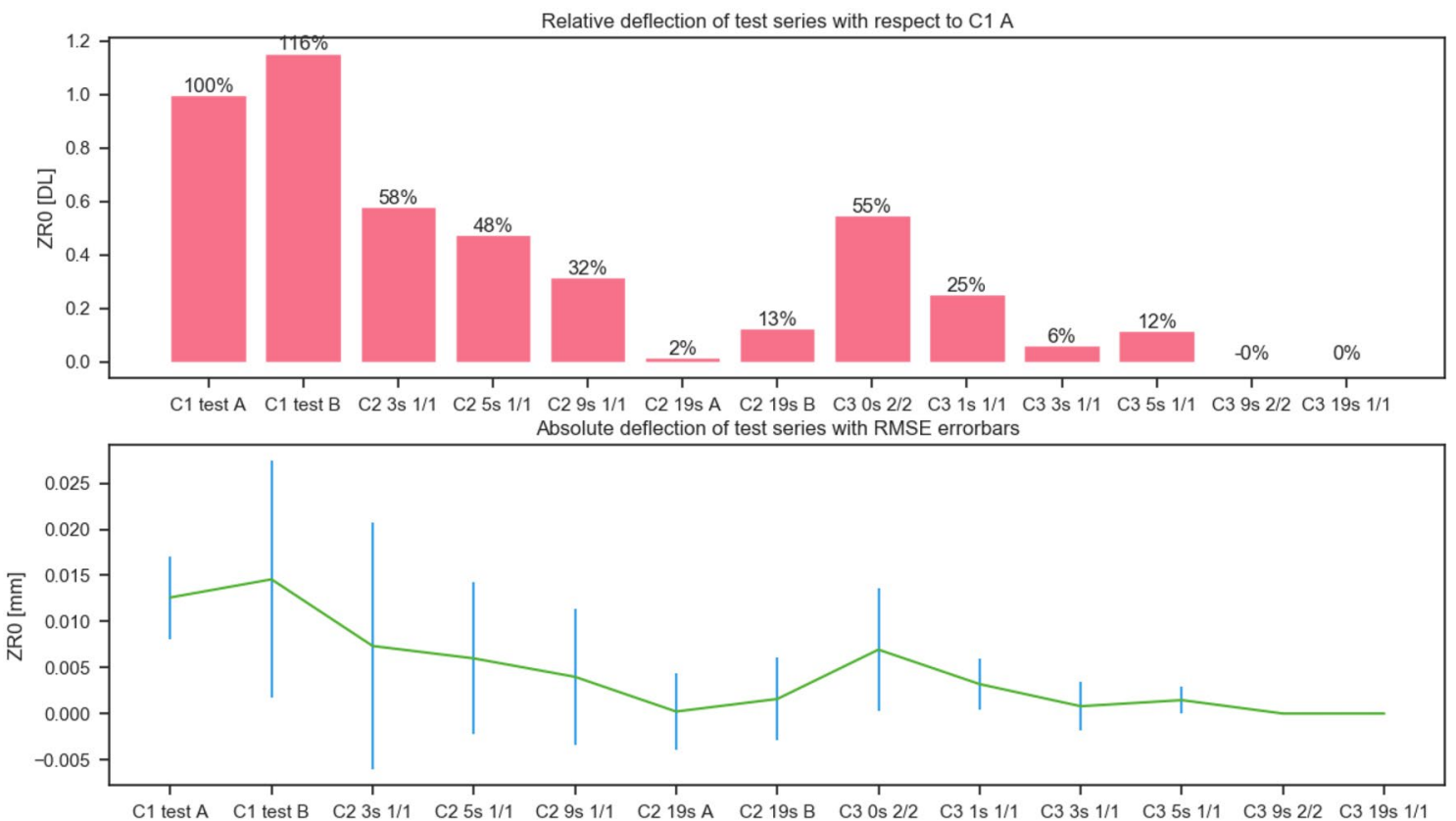

Fig. 13 Relative and absolute deflection with errorbar for ZR0

the unloaded floor to be vulnerable not only to intersecting flanges of $\mathrm{C} 3$, but also to the stiffness of the connection to the columns (torque on MRC bolts), see Fig. S8.

The relative vertical deflection between adjacent floor elements unveils the most distinctive results from the test (see Fig. 13 and ESM). The Pareto chart (Fig. S9) shows significance of both configuration and screws as expected. Furthermore, the magnitude as expressed in the main effects chart (Fig. S10) is unambiguous and easy to interpret. Upper left panel of the interaction chart shows valuable information (Fig. S11): For configuration domain 1 to 2: Changing torque has less significance for the first configuration. Effect of an increasing number of screws is not as apparent for $\mathrm{C} 3$ as for $\mathrm{C} 2$. With respect to unconnected elements, five screws in $\mathrm{C} 3$ will cause an $80 \%$ reduction in the displacement between adjacent floor elements, while for $\mathrm{C} 2$ it only causes $50 \%$ reduction. Bear in mind, $\mathrm{C} 2$ requires four rows of screws whilst $\mathrm{C} 3$ only two, hence $\mathrm{C} 2$ will consume twice the amount of workforce and screws as $\mathrm{C} 3$ for installation.

Concerning the rotation about longitudinal axis between adjacent edges (see ESM), torque is as expected not significant, but the configuration and the shear capacity of the connection (i.e., number of screws) are dominating (see Fig. S12). The main effects plot (Fig. S13) clearly shows the effect of configurations and the number of screws and that the rotation is increasing from $\mathrm{C} 1$ to $\mathrm{C} 2$ as the flanges are increasingly tied together with loose flange boards, and that the same effect is seen for C3. The deformation pattern is as expected because adjacent longitudinal edges follow a quadrilateral pattern for $\mathrm{C} 2$, whilst for $\mathrm{C} 3$ vertical deformation from the loaded floor is efficiently transferred to the unloaded floor. For C3, this causes the unloaded floor to be deformed more, thus increasing the relative rotation between the floors because the stiffness of the intersecting flange is smaller than the stiffness of the floor elements (see Fig. 14). The analysis of rotational deflection indicates that neither of the present longitudinal interconnections can transfer significant bending moment between the floor elements.

\subsubsection{Floor elements in series}

For floor elements in series the following trends are seen: Both ZA1 and ZAmean7and8 are responding similarly and with similar statistical results. The discussion is based on charts for the latter (see Fig. 15). The deflection is responding rapidly on the first number of screws particularly on top of the bridge. Already at three screws, the deflection is transmitted from loaded floor to unloaded floor with $80 \%$ of the expected potential. The observed effect of bottom nail plate with respect to nail plate on top for transmitting deflection is likely to be connected to the censoring point, which is on the bottom flange (Fig. S14). The response shows no noteworthy interaction of factors, hence not discussed.

As for the deflection of the unloaded floor (see ESM), the midspan deflection is also responding rapidly on the first number of screws (Fig. S15), but the responding mechanisms are different: The deflection is increasing as the floors are tied together, but as the moment stiffness is further 

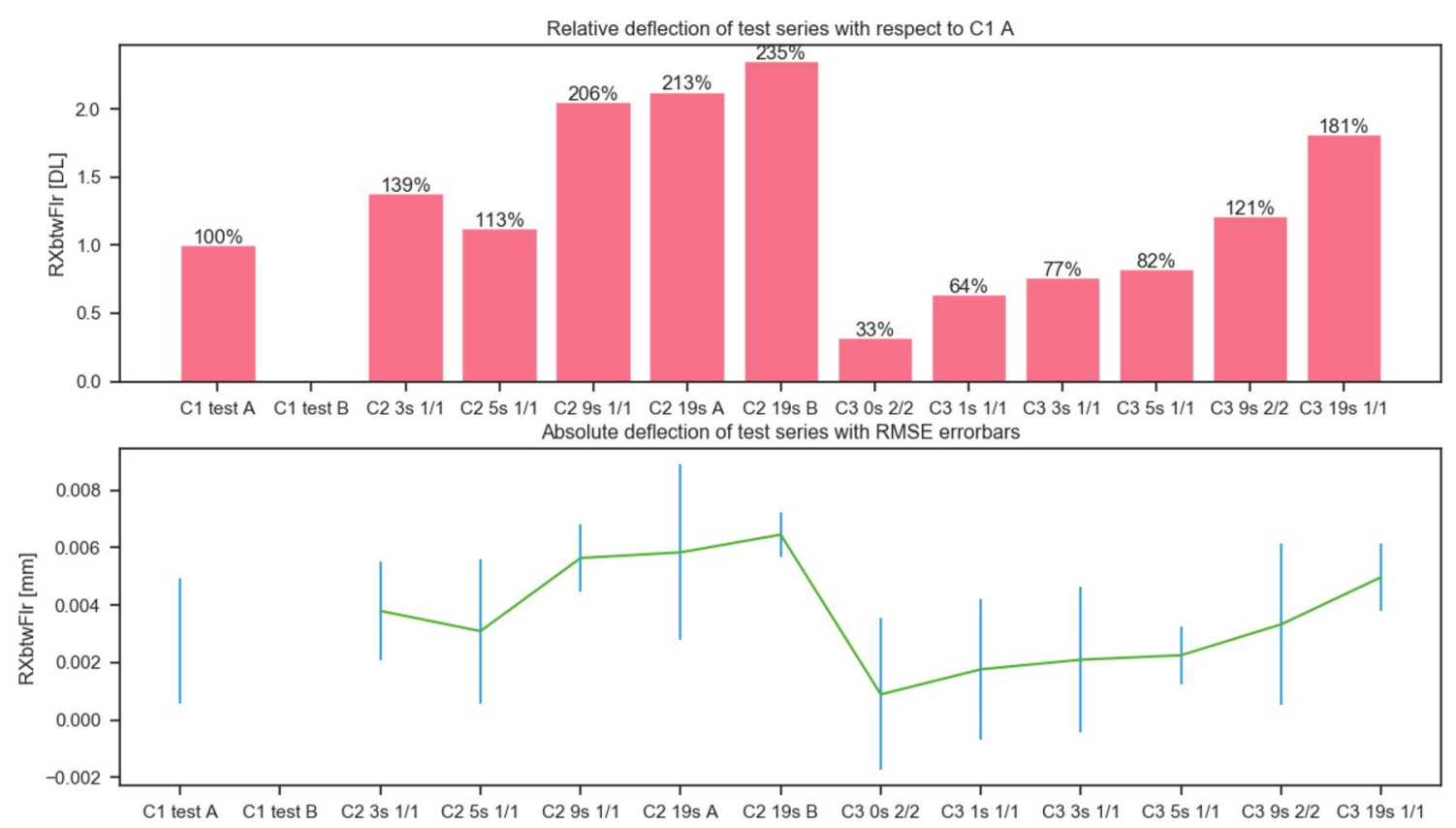

Fig. 14 Rotation about longitudinal axis between adjacent edge joists (RXbtwFlr)

\section{Relative and absolute deflection with errorbar (RMSE) for ZAmean7and8}
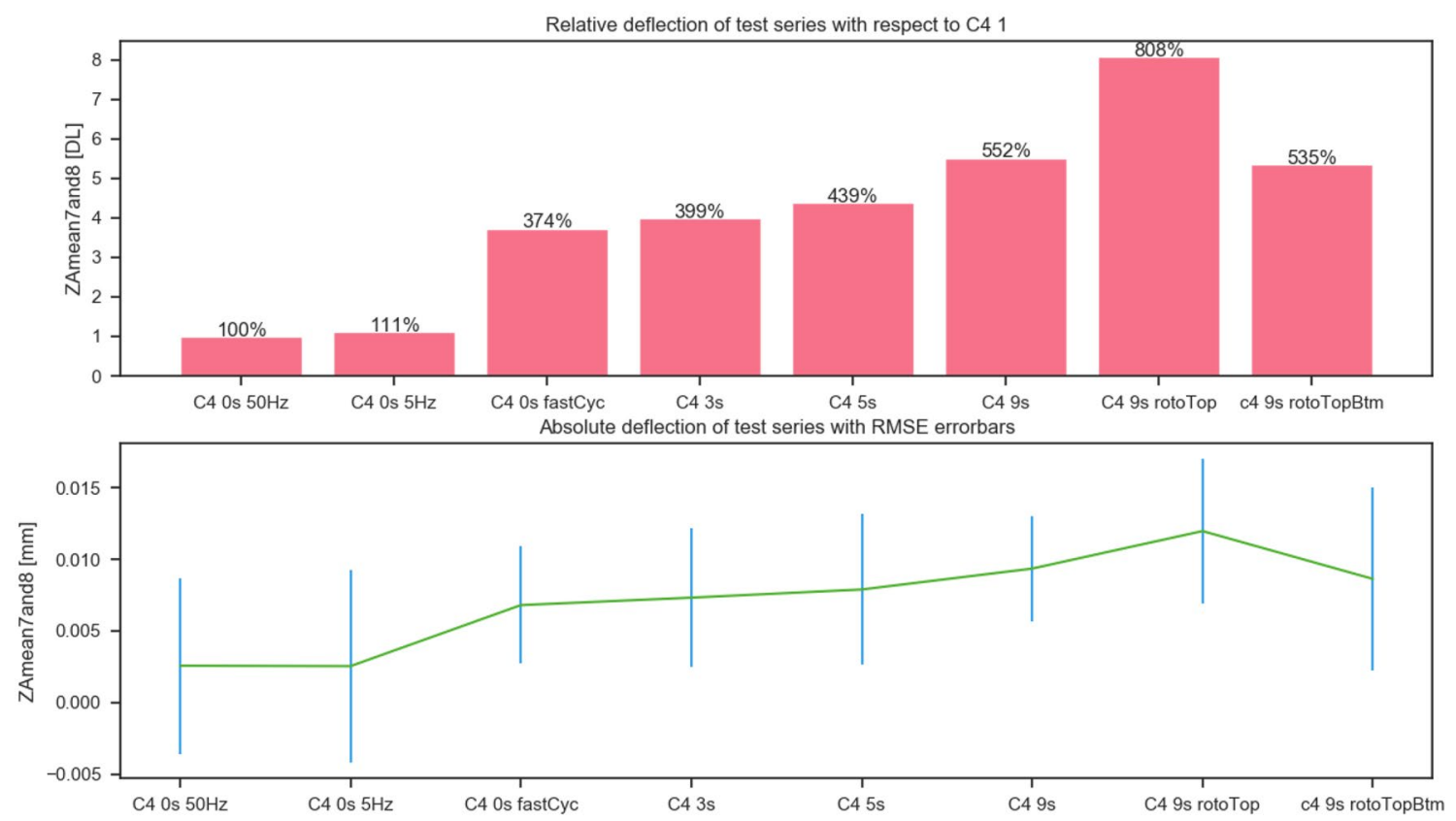

Fig. 15 Relative and absolute deflection with errorbar for ZAmean7and8

increased either with nine screws at top and bottom, or nail plates on both levels, the deflection decreases (Fig. S16). This phenomenon is as expected and is distinctively also seen in the relative rotation between the floor elements in Fig. S17.
As can be seen in Fig. 16, the relative rotation is responding nicely to increased stiffness between the floor elements, but the effect requires nine screws to be substantial ( $45 \%$ of the rotation of the unconnected case). The nail plate added in the three last runs is equally efficient as nine screws, but 
Relative and absolute deflection with errorbar (RMSE) for RYbtwFIr

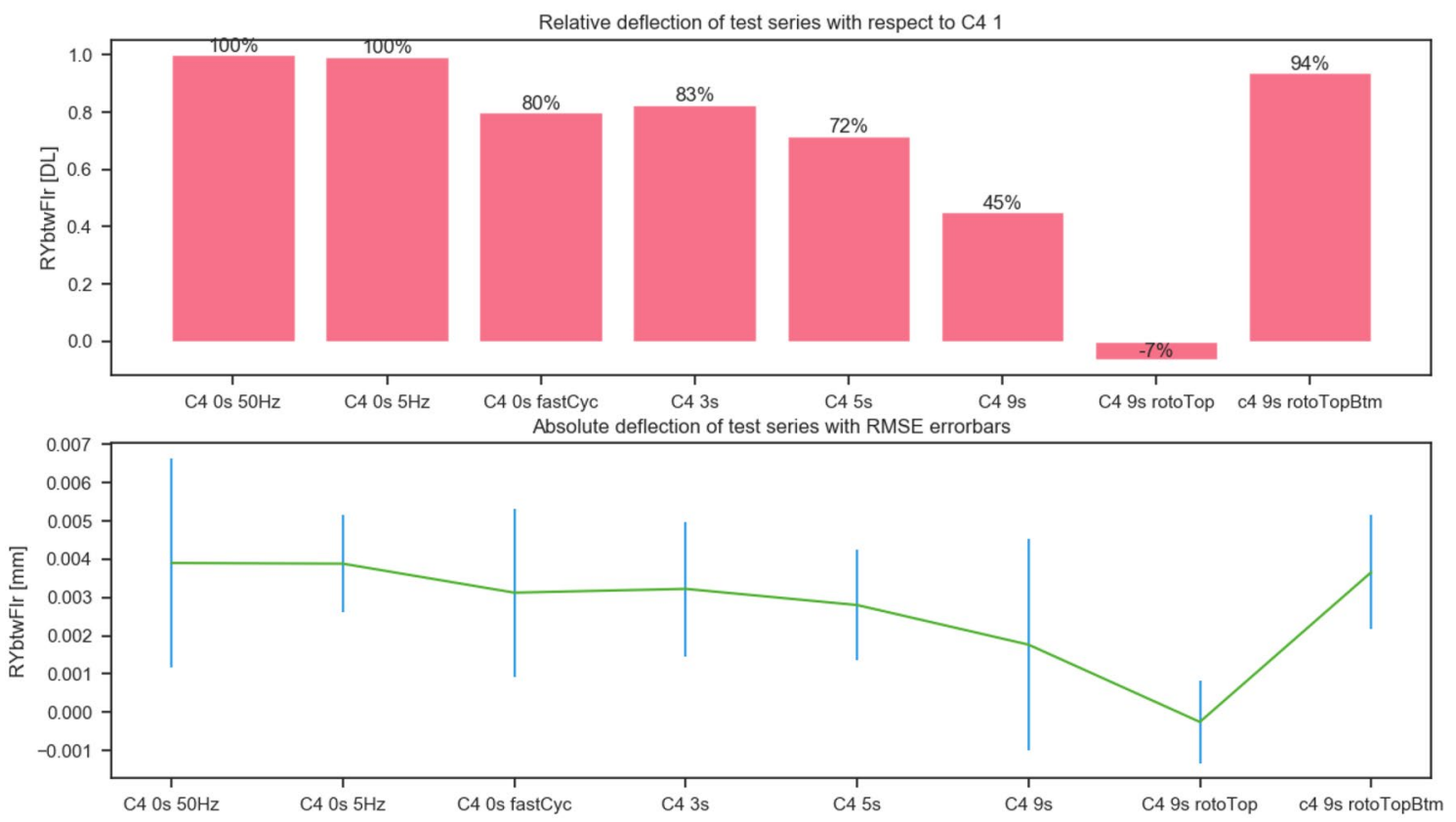

Fig. 16 Relative and absolute deflection with error bar for RYbtwFlr

it requires as expected a force couple on top and bottom (see difference on two runs to the right of Fig. 16 as well as left panel on the interaction chart Fig. S17).

\subsection{Numerical modelling of interconnection}

The numerical modelling of the floor elements used in the present work is studied in Nesheim and Malo (2018). The modelling of the MRC was done in accordance with results from testing of the MRC at NTNU. The interconnections were modelled as simplified shell elements tied to the flanges also modelled as shell elements as no alterations were studied in the numerical representation of the interconnections. Interconnections can more accurately be modelled as spring elements to better reflect changes in the stiffness of the interconnection, but for the present work the simplified modelling sufficed to see the dominating variations between the different configurations. If, however changes to a particular interconnection was to be studied, the numerical modelling must have been modelled more accurately.

\section{Conclusion}

Dynamic and static evaluations of the effect of interconnection on various configurations of two full-scale floor elements have revealed several cohesions. Investigation of results has focused on effects that can aid as resource-efficient approach of manipulating vibration serviceability performance without any significant increase in cost or carbon emission for the flooring system. The present work can aid in the understanding of how the dynamic responses shift as interconnections and orientations of floor elements change, and the principle can aid in standardization of floor elements as one design can be utilized in flooring systems with amendable comfort properties. Generally, fundamental mode shapes of the floor elements acting as unconnected entities are observed to persist, but their resonant energy is lowered depending on the interconnection. Ignoring the effects of interconnections may cause considerable misjudgement in the assessment of vibration serviceability performance of the flooring system. Due to the range of configurations and effects, key findings are condensed from the discussion and presented schematically in Table 10 . The table is split to have floor elements in parallel and series in separate columns, and with category of effects in separate rows. Each of the key findings of Table 10 contains a reference to the associated paragraph of the discussion.

In general, a strong interconnection will increase fundamental frequency with respect to an isolated similar floor element and increase the performance of the flooring system as quantified by the $\mathrm{Hu}$ and Chui criterion. For resonant floor design situations (acceleration dominated perception), increased stiffness of the interconnection will increase damping and consequently reduce accelerations. Depending on the fundamental frequency, it is a likely 
Table 10 Schematic presentation of key findings

\begin{tabular}{|c|c|c|}
\hline Effect & Floor elements in parallel & Floor elements in series \\
\hline \multirow[t]{3}{*}{ Frequency } & $\begin{array}{l}\text { Increased interconnection stiffness } \\
\text { reduces Eigen frequency of longitu- } \\
\text { dinal mode shapes, shifting towards } \\
\text { resonant response }(4.1 .1 \Phi[1)\end{array}$ & $\begin{array}{l}\text { For each mode order, both longitudinally and transversally, the eigen frequency is } \\
\text { increasing with increasing bending stiffness of the interconnection }(4.1 .2 \Psi 1)\end{array}$ \\
\hline & $\begin{array}{l}\text { Increased interconnection stiffness } \\
\text { yields a shift in Eigen frequency of } \\
\text { transverse mode shapes upwards close } \\
\text { to } 10 \%(4.1 .1 \mathrm{~g}[2)\end{array}$ & \\
\hline & $\begin{array}{l}\text { Frequency spacing between adjacent } \\
\text { modes decrease with increasing stiff- } \\
\text { ness of the interconnection }(4.1 .1 \llbracket 6)\end{array}$ & $\begin{array}{l}\text { No significant correlation is observed between the stiffness of the connection and the } \\
\text { frequency spacing of adjacent modes }\end{array}$ \\
\hline \multirow{3}{*}{$\begin{array}{l}\text { Damping gener- } \\
\text { ally }\end{array}$} & \multicolumn{2}{|c|}{ Damping increase with increasing mode order $(4.1 .1 \Phi[5,4.1 .2 \Phi[2)$} \\
\hline & \multicolumn{2}{|c|}{$\begin{array}{l}\text { For comparable mode shapes, damping increase with increasing stiffness of interconnection, provided that both shear and } \\
\text { bending is transferred }(4.1 .1,4.1 .2)\end{array}$} \\
\hline & No information available & Damping tend to be higher with nail plates than with flange head screws (4.1.2I[3) \\
\hline Material damp- & \multicolumn{2}{|c|}{ Mode shapes associated with bending generally cause low damping (see 4.1.1 I[1) } \\
\hline & \multicolumn{2}{|c|}{ Mode shapes associated with floor element torsion efficiently increase damping (4.1.1q[4) } \\
\hline Structural & \multicolumn{2}{|c|}{ Mode shapes activating interconnection axial stress cause no significant contribution to damping (4.1.1 II2) } \\
\hline damping & \multicolumn{2}{|c|}{ Mode shapes activating shear stress either in the interconnection or the floor elements render high damping (4.1.19[3) } \\
\hline $\begin{array}{c}\text { Resonant } \\
\text { energy }\end{array}$ & \multicolumn{2}{|c|}{$\begin{array}{l}\text { Resonant energy is flattened as interconnection gain stiffness: Susceptibility to resonance from single frequency source is } \\
\text { reduced as the response characteristics are flattened (4.1פ[2) }\end{array}$} \\
\hline $\begin{array}{l}\text { Deflection } \\
\text { transfer }\end{array}$ & $\begin{array}{l}\text { Intersecting flanges }(\mathrm{C} 3) \text { is the pro- } \\
\text { posed solution for design situations } \\
\text { requiring good load distribution. } \\
\text { Screws are more effectively utilised } \\
\text { in C3 than in board interconnection. } \\
\text { Only five screws in C3 will cause an } \\
80 \% \text { reduction of the displacement } \\
\text { between adjacent floor elements } \\
(4.2 .1 \Phi[1,2)\end{array}$ & $\begin{array}{l}\text { Already at three screws per row on the bridging component, deflection from loaded } \\
\text { to unloaded floor element is transmitted with } 80 \% \text { of the expected potential. Add- } \\
\text { ing more screws is likely not an economic measure (4.2.2đ1) }\end{array}$ \\
\hline $\begin{array}{l}\text { Bending trans- } \\
\text { fer }\end{array}$ & $\begin{array}{l}\text { The longitudinal interconnections } \\
\text { do not have the structural capacity } \\
\text { of transferring significant bending } \\
\text { moment between the floor elements } \\
(4.2 .1 \Phi[3)\end{array}$ & $\begin{array}{l}\text { The interconnection must transfer moment to realize significant effect. (4.1.2II4). } \\
\text { Either nine screws or nail plates on both top and bottom suffice. Further fastening } \\
\text { is likely not cost-effective (4.2.2I3) }\end{array}$ \\
\hline
\end{tabular}

measure to shift acceleration levels considerably down. For transient floor design situations (velocity dominated perception) both increased damping and increased fundamental frequency will contribute to decrease velocity response. The concurrent effect from both would contribute effectively to decrease velocity response.

Experiments executed in this study suffer from low amplitude dynamic response due to short span floor elements primarily built for testing acoustic performances (Conta and Homb 2020). Several sensors have readings lower than the accuracy of the sensor and are disregarded. For a future opportunity of full-scale testing of long spanning floor elements, a design of experiment that can validate the findings herein would be valuable. Keeping all floor elements of same size would help in revealing mechanisms with enhanced general validity. An interesting topic could also be to investigate the effect of combining strong and weak direction of the floor elements, both due to the flexibility the configuration may add to the floor plan, but also due to the increased system and torsional damping. Due to the findings of damping related to torsion, combining floor elements in reciprocal configurations that induce torsional deflections may yield flooring system with high damping. These studies would all provide valuable information for resource-efficient measures of adapting standardized floor elements to a wide range of applications.

Supplementary Information The online version contains supplementary material available at https://doi.org/10.1007/s00107-021-01709-y.

Acknowledgements This work is part of the four-year project "WoodSol-Wood frame solutions for free space design in urban buildings" realized through the research grant from The Research Council of Norway (254699/E50). The support is gratefully acknowledged. The authors would also like to acknowledge the contribution by fellow 
doctoral students Aivars Vilguts and Simone Conta in the preparation and execution of the work.

Author contributions For the original article presented herein, all authors have contributed to its preparation as described in the below statement: SN: conceptualization, methodology, software, validation, investigation, resources, writing — original draft, writing — review and editing, visualization, project administration. KAM: writing-review and editing, supervision, funding acquisition. NL: review and editing, supervision.

Funding Open access funding provided by NTNU Norwegian University of Science and Technology (incl St. Olavs Hospital - Trondheim University Hospital).

Data availability The data from measurements and codes used herein is made available under standard publication license Attribution 4.0 International (CC BY 4.0) at https://bird.unit.no/. The data from testing and codes for analysing structural response for the present work is found here: https://hdl.handle.net/11250/2724776.

\section{Declarations}

Conflict of interest The authors declare that they have no known competing financial interests or personal relationships that could have appeared to influence the work reported in this paper. The authors declare that no financial interests or personal relationships may be considered as potential competing interests.

Open Access This article is licensed under a Creative Commons Attribution 4.0 International License, which permits use, sharing, adaptation, distribution and reproduction in any medium or format, as long as you give appropriate credit to the original author(s) and the source, provide a link to the Creative Commons licence, and indicate if changes were made. The images or other third party material in this article are included in the article's Creative Commons licence, unless indicated otherwise in a credit line to the material. If material is not included in the article's Creative Commons licence and your intended use is not permitted by statutory regulation or exceeds the permitted use, you will need to obtain permission directly from the copyright holder. To view a copy of this licence, visit http://creativecommons.org/licenses/by/4.0/.

\section{References}

Abeysekera I, Hamm P, Toratti T, Lawrence A (2019) Development of a floor vibration design method for Eurocode 5. N Z Timber Des 27(1)

Adams RD, Bacon D (1973) Measurement of the flexural damping capacity and dynamic Young's modulus of metals and reinforced plastics. J Phys D Appl Phys 6(1):27

Anco Engineers Inc (2010) Operating manual for the MK-102 eccentric mass vibrator system. Anco Engineers Inc, Boulder, p 26

Brüel and Kjær (2012) Heavy duty impact hammer-type 8210, Brüel\&Kjær Sound and Vibration Measurement A/S

Burch H, Sanchez S, Ebrahimpour A (2016) Serviceability sensitivity analysis of wood floors allowing for sheathing discontinuities. Wood Fiber Sci 48:17-21

CEN (2018a). EN 1995-1-1 SC5.T3 milestone draft 2 Revised section 9.3. Revised section 9.3. Brussels, European committee for standarization

CEN (2018b). EN 16929 Test methods-timber floors-determination of vibration properties, European Committee for Standardization.
Conta S, Homb A (2020) Sound radiation of hollow box timber floors under impact excitation: an experimental parameter study. Appl Acoust 161:107190

Dassault Systèmes (2017) Abaqus CAE, Dassault Systèmes Simulia corp

Dynea (2017) Prefere 4094 Technical Data Sheet. Liquid, gap filling phenol-resorcinol adhesive for the wood industry. Dynea

Ebadi MM (2017) Vibration behaviour of glulam beam-and-deck floors. PhD Article, Univ. of Ottawa

Ebadi MM, Doudak G, Smith I (2016) Dynamic characteristics of glulam beam and deck-element floors. In: 2016 World Conference on Timber Engineering, Vienna University of Technology

Ebadi MM, Doudak G, Smith I (2017) Finite-element modeling and parametric study of glulam beam-and-deck floors. J Struct Eng (US) 143(9):4017106

Gosling J, Sassi P, Naim M, Lark R (2013) Adaptable buildings: a systems approach. Sustain Urban Areas 7:44-51

HBM (2019a) Inductive standard displacement transducers WA2, Hottinger Baldwin Messtechnik GmbH

HBM (2019b) U2B 50 kN Force Transducer, Hottinger Baldwin Messtechnik GmbH

Hu LJ, Chui YH (2004) Development of a design method to control vibrations induced by normal walking action in wood-based floors. In: Proceedings of the 8th World Conference on Timber Engineering. Lahti, Finland. 2:217-222

ISO (2007) ISO 10137:2007 Bases for design of structures-serviceability of buildings and walkways against vibrations, International Organization for Standardization

Kistler (2008) Ceramic/quartz impedance head for modal analysis type 8770A. 8770A_000-252-07.08. Switzerland, Kistler Group

Labonnote N, Malo KA (2010) Vibration properties of cross laminated timber floors. Struct Archit 428-435

Labonnote N, Rønnquist A, Malo KA (2013) Experimental evaluations of material damping in timber beams of structural dimensions. Wood Sci Technol 47(5):1033-1050

Labonnote N, Ronnquist A, Malo KA (2015) Prediction of material damping in timber floors, and subsequent evaluation of structural damping. Mater Struct 48(6):1965-1975

Negreira J, Trollé A, Jarnerö K, Sjökvist LG, Bard D (2015) Psychovibratory evaluation of timber floors - towards the determination of design indicators of vibration acceptability and vibration annoyance. J Sound Vib 340:383-408

Nesheim S, Malo KA (2018) Assessing adequacy of numerical representation for optimisation performances in long span timber floors. In: World Conference in Timber Engineering 2018, Seoul

Ohlsson S (1988) Springiness and human-induced floor vibrations. A design guide. Document D12-Swedish Council for Building Research, Stockholm Sweden (12)

Pavelka P, Hunady R, Hagara M, Trebuna F (2015) Reciprocity in experimental modal analysis. Am J Mech Eng 3(6):252-256

Smith AL, Hicks SJ, Devine PJ (2009) Design of floors for vibration: a new approach. SCI, Ascot

Stamatopoulos H, Malo K (2018) Wood frame solutions for free space design in urban buildings (WOODSOL). In: 7th Forum Wood Building Nordic, Växjö, Sweden

Ungar EE, Kerwin EM Jr (1962) Loss factors of viscoelastic systems in terms of energy concepts. J Acoust Soc Am 34(7):954-957

Ussher E, Arjomandi K, Weckendorf J, Smith I (2017) Prediction of motion responses of cross-laminated-timber slabs. Structures 11:49-61

Vilguts A, Malo KA, Stamatopoulos H (2018) Moment resisting frames and connections using threaded rods in beam-to column timber joints. In: World Conference on Timber Engineering, Seoul, Republic of Korea 
Weckendorf J, Smith I (2012) Dynamic characteristics of shallow floors with cross-laminated-timber spines. In: World Conference on Timber Engineering 2012, WCTE 2012

Weckendorf J, Hafeez G, Doudak G, Smith I (2014) Floor vibration serviceability problems in wood light-frame buildings. J Perform Const Facil 28(6)

Weckendorf J, Toratti T, Smith T, Tannert T (2016a) Vibration serviceability performance of timber floors. Eur J Wood Prod 74(3):353-367

Weckendorf J, Ussher E, Smith I (2016b) Dynamic response of CLT plate systems in the context of timber and hybrid construction. Compos Struct 157:412-423
Welch P (1967) The use of fast Fourier transform for the estimation of power spectra: a method based on time averaging over short, modified periodograms. IEEE Trans Audio Electroacoust 15(2):70-73

Zhang B, Rasmussen B, Jorissen A, Harte A (2013) Comparison of vibrational comfort assessment criteria for design of timber floors among the European countries. Eng Struct 52:592-607

Publisher's Note Springer Nature remains neutral with regard to jurisdictional claims in published maps and institutional affiliations'. 